\title{
Seasonal Wind Characteristics and Prospects of Wind Energy Conversion Systems for Water Production in the Far North Region of Cameroon
}

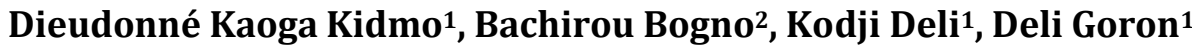 \\ ${ }^{1}$ National Advanced School of Engineering, University of Maroua, Maroua, Cameroon \\ ${ }^{2}$ Higher Teacher's Training College, University of Maroua, Maroua, Cameroon \\ Email: kidmokao@gmail.com
}

How to cite this paper: Kidmo, D.K., Bogno, B., Deli, K. and Goron, D. (2020) Seasonal Wind Characteristics and Prospects of Wind Energy Conversion Systems for Water Production in the Far North Region of Cameroon. Smart Grid and Renewable Energy, 11, 127-164.

https://doi.org/10.4236/sgre.2020.119009

Received: August 6, 2020

Accepted: September 27, 2020

Published: September 30, 2020

Copyright $\odot 2020$ by author(s) and Scientific Research Publishing Inc. This work is licensed under the Creative Commons Attribution International License (CC BY 4.0).

http://creativecommons.org/licenses/by/4.0/

(c) (i) Open Access

\begin{abstract}
This study aimed at investigating the characteristics of the wind power resource in the Far North Region of Cameroon (FNR), based on modelling of daily long-term satellite-derived data (2005-2020) and in-situ wind measurements data (1987-2020). Five different reliable statistical indicators assessed the accuracy level for the goodness-of-fit tests of satellite-derived data. The two-parameter Weibull distribution function using the energy factor method described the statistical distribution of wind speed and investigated the characteristics of the wind power resource. Six 10-kW pitch-controlled wind turbines (WT) evaluated the power output, energy and water produced. A $50 \mathrm{~m}$ pumping head was considered to estimate seasonal variations of volumetric flow rates and costs of water produced. The results revealed that the wind resource in FNR is suitable only for wind pumping applications. Based on the hydraulic requirements for wind pumps, mechanical wind pumping system can be the most cost-effective option of wind pumping technologies in FNR. However, based on the estimated capacity factors of selected WT, wind electric pumping system can be acceptable for only four out of twenty-one sites in FNR.
\end{abstract}

\section{Keywords}

In Situ Wind Measurements, Mechanical Wind Pumping, Wind Electrical Pumping, Satellite-Based Wind Resource, Wind Energy, Far North Cameroon 


\section{Introduction}

Wind has nowadays become a stable form of power supply and is considered as one of the most cost-effective means for delivering low-carbon energy services, particularly to the most vulnerable segments of the population in numerous developing nations. It's anticipated that by 2050 , wind power could contribute to more than $25 \%$ of the total emissions reductions needed (approximately 6.3 gigatons of carbon dioxide annually), under the energy goals set out in the United Nations 2030 Agenda and the Paris Agreement. Wind energy (WE) would then generate more than $35 \%$ of total electricity needs, becoming the prominent generation source by 2050 [1].

Over the last two decades, the yearly growth rate of global WE has been as high as $38.56 \%$ (2001), as low as $9.61 \%$ (2018) and on average $22 \%$. At the end of 2019, global WE generation capacity amounted to 622.7 gigawatts (GW), which represented $25 \%$ of renewable generation capacity by energy source. Hydropower, the largest share of the global total, accounted for $47 \%$ (1190 GW), while the share of solar reached 23\% (586 GW) in 2019 [2]. Globally, WE performed particularly well in 2019, expanding by 58.9 GW (10.44\%). Asia accounted for $49.47 \%$ of new capacity in 2019, increasing its WE generation capacity by 29.13 GW to reach $258.32 \mathrm{GW}$ ( $41.48 \%$ of the global total). WE capacity in Europe and North America expanded by $14.02 \mathrm{GW}(+31.46 \%)$ and $11.48 \mathrm{GW}(+19.85 \%)$, respectively [3]. Oceania and the Middle East were the fastest growing regions $(+22.18 \%$ and $+17.75 \%$, respectively), with $2.47 \%$ and $0.19 \%$, representing their share of global WE capacity, respectively. Africa accounted for $0.51 \%$, the lowest of new capacity in 2019, increasing its wind energy capacity by only $0.3 \mathrm{GW}$ to reach $5.7 \mathrm{GW}$ (0.93\% of the global total). Compared to 2018, capacity growth in Africa and Middle East was somewhat lower than in 2019, but higher in Asia, Europe and North America [3].

Despite being the least growing region in terms of WE generation capacity, Africa has WE resources and potential that can meet its current needs, if properly tapped. Several studies have shown that the wind resource in Africa is greatest around the coasts and in the eastern highlands [4] [5]. However, the WE development in the African continent remains very slow as a result of limited support at the level of the continent, since the vast majority of WE projects necessitate financial support from organizations based out of the continent [6]. By the end of 2019, North Africa and the Republic of South Africa continued to dominate, with $49.44 \%(2.85 \mathrm{GW})$ and $36.32 \%(2.09 \mathrm{GW})$, representing their share of WE capacity in the African continent.

Sub-Saharan Africa, accounted for 14.24\%, representing the lowest share of WE capacity. At roughly $0.82 \mathrm{GW}$, the entire WE generating capacity of the 47 countries of sub-Saharan Africa (excluding the Republic of South Africa), is less than that of Morocco. As a result, sub-Saharan Africa has the world's lowest WE generation capacity, despite the wind potential that is essentially untapped. Furthermore, transition-related clean energy investments in Sub-Saharan Africa is 
one of the lowest worldwide, about USD 50 per capita per year, while the average is around USD 122 per capita per year [7]. Moreover, sub-Saharan Africa displays the lowest electricity access of only $45 \%$, far lower than the world average of $89 \%$. Furthermore, the vast majority of people (over 99\%) deprived of electricity are in developing nations, and four-fifth of them live in rural South Asia and sub-Saharan Africa [8].

Similarly, Cameroon, does not have any installed WE capacity, despite the existing potential. Neighboring countries with comparable wind potential, have taken steps in exploring wind power. By the end of 2019, WE generation capacity in Chad and Nigeria amounted to approximately 1 and 3 megawatts (MW), respectively [3]. Most of the analyses performed to assess the potential of wind power have shown that the whole country lays in low wind resources regime, with very limited high wind sites. The vast majority of sites fall under poor to marginal wind regime. However, detailed information on the potential wind resource, which is of paramount importance when forecasting wind power for the optimal site selection, has yet to be precisely acknowledged. Locally measured wind data are generally available at meteorological stations located at the main airports, while there are no ground station measurements for the vast majority of locations which are far (at least $50 \mathrm{~km}$ ) from the main airports.

When meteorological measured wind data from masts are missing, wind resource estimation using daily long-term satellite-derived data are considered [9] [10] [11]. Furthermore, for comparison analysis, both meteorological observations and satellite-derived data are used to estimate the local accuracy [12] [13] [14].

All things considered, the proposed work aims at investigating the characteristics of wind power resource from twenty-one locations in FNR, using daily long-term satellite-derived data for the period 2005-2020 and 3-hourly time step observed wind speed data from 02 weather recording locations (Kousseri and Maroua) for the period 1987-2020. The main objective of this study is to provide a reasonable wind power resource assessment in the early phase of wind farm projects using satellite-based wind resource, before higher-accuracy in-situ measurements are available. Furthermore, the accuracy level of satellite-based wind resource is assessed using mean bias error (MBE), root mean square error (RMSE), relative root mean square error (RRMSE), coefficient of determination $\left(R^{2}\right)$ and index of agreement (IOA). The two-parameter Weibull distribution function using the energy factor method has been considered to investigate the characteristics of the wind power resource. Six 10-kW pitch-controlled wind turbines (WT) with a hub height of $30 \mathrm{~m}$, are considered to evaluate the power output and energy produced. Seasonal variations of volumetric flow rates and costs of water produced are estimated using a $50 \mathrm{~m}$ pumping head, for the sake of simplicity. The results show that the wind resource in FNR is deemed suitable for wind pumping applications. Based on the hydraulic requirements for wind pumps, mechanical wind pumping system can be the most cost-effective option of wind 
pumping technologies in all twenty-one sites. However, based on the estimated capacity factors of selected WT, wind electric pumping system can be acceptable for four sites (Blangoua, Goulfey, Hilé-Alifa and Kousseri). The novelty of this study is the exploration of wind resource for wind pumping applications in twenty-one locations in FNR and the study of six selected pitch-controlled WT to take full advantage of costs of energy and water produced, based on modelling of daily long-term satellite-derived data for the period 2005-2020.

\section{Methodology}

\subsection{Description of Far North Region of Cameroon}

Figure 1 shows FNR, the northernmost region of the Republic of Cameroon, which covers a surface area of $34,263 \mathrm{~km}^{2}$. It borders the north region (Cameroon) to the south, Borno and Adamawa states (Nigeria) to the west, N'Djamena, Lake, Hadjer-Lamis, Chari-Baguirmi, east and west Mayo-Kebbi regions (Chad) to the east. According to the Cameroon statistical year book of the year 2017, FNR has a population of $4,186,844$, with a density of 122.2 persons per square kilometers [15]. Located in a semi-arid sudano-sahelian climate, FNR is characterized by annual rainfall of between $400-900 \mathrm{~mm}$ during the rainy season that lasts about four months, between July and October [16]. The rainfall patterns in the region are remarkably unpredictable, with flooding when excess of rainfall is observed or droughts when deficit of rainfall is recorded. From November to June, eight months of dry season is observed, with strong wind (Harmattan) followed by dry and hot weather [17]. Most of FNR lies at a moderate relief with low elevation, about 500 meters in the southwest and 200 meters at the Logon river.

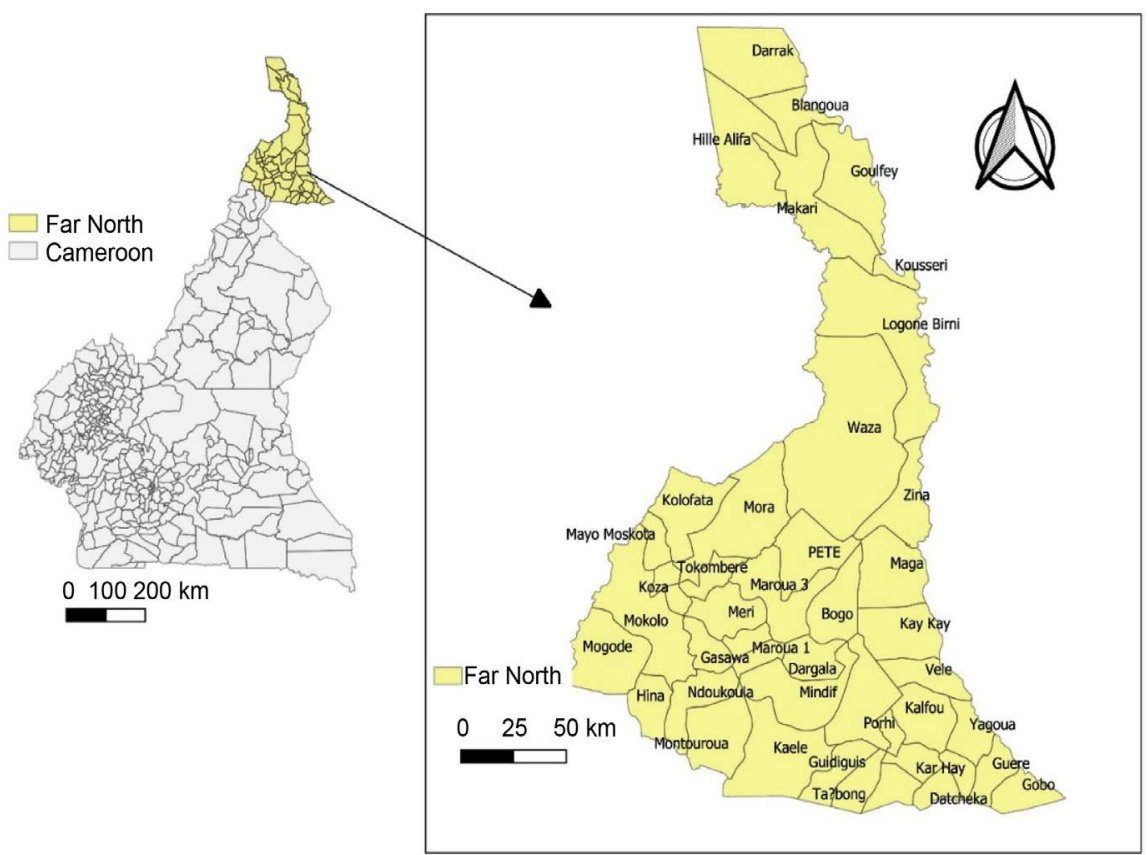

Figure 1. Map of FNR, developed by the authors using QGIS 2.18.3 software. 
Nevertheless, there are a number of isolated inselbergs, namely, the Mandara mountains at the Nigerian borders in the southwest, with an elevation in the range of $500-1000$ meters. FNR is located in a practically flat terrain for which the wind flow is considered within the scope of linear models for vertical extrapolation of wind speed data.

\subsection{Wind Data Description and Source}

For this study, in situ measurements (3-hourly time step observed wind speed data) from 02 weather recording locations at Kousseri and Maroua for the period 1987-2020 and daily long-term satellite-derived data for the period 2005-2020, are utilized. In situ and satellite measurements were recorded at a height of 10 meters height above ground level (agl). With the exception of Kousseri and Maroua, it appears that wind speed recording instruments are non-existent in the rest of the nineteen other considered sites of FNR. Thus, the use of long-term daily satellite-derived data, obtained from the NASA Langley Research Center (LaRC) POWER Project funded through the NASA Earth Science/Applied Science Program [18]. Table 1 provides geographical coordinates of the twenty-one sites considered, as well as satellite and in situ measurements periods.

Table 1. Geographical data for twenty-one selected locations in FNR.

\begin{tabular}{cccccc}
\hline Location & Latitude $\left(^{\circ}\right)$ & $\begin{array}{c}\text { Longitude } \\
\left({ }^{\circ}\right)\end{array}$ & $\begin{array}{c}\text { Elevation } \\
(\mathrm{m})\end{array}$ & $\begin{array}{c}\text { Satellite } \\
\text { measurements } \\
\text { period }\end{array}$ & $\begin{array}{c}\text { In situ } \\
\text { Measurements } \\
\text { period }\end{array}$ \\
\hline Bogo & 10.7446 & 14.5953 & 349.93 & Jan 2005-Jan 2020 & \\
Gazawa & 10.2457 & 14.8378 & 360.61 & Jan 2005-Jan 2020 & \\
Maroua & 10.583 & 14.3351 & 428.67 & Jan 2005-Jan 2020 & Jan 1987-Jan 2020 \\
Ndoukoula & 10.27 & 14.0397 & 425.44 & Jan 2005-Jan 2020 & \\
Blangoua & 12.7732 & 14.5419 & 287.09 & Jan 2005-Jan 2020 & \\
Darak & 11.0242 & 14.5191 & 320.68 & Jan 2005-Jan 2020 & \\
Fotokol & 12.3785 & 14.2287 & 291.47 & Jan 2005-Jan 2020 & \\
Goulfey & 12.3829 & 14.8923 & 292.02 & Jan 2005-Jan 2020 & \\
Hile-Alifa & 12.6863 & 14.3095 & 285.82 & Jan 2005-Jan 2020 & \\
Kousséri & 12.0506 & 15.0254 & 294.83 & Jan 2005-Jan 2020 & Jan 1987-Jan 2020 \\
Logone-Birni & 11.7917 & 15.0993 & 302.58 & Jan 2005-Jan 2020 & \\
Gobo & 9.9993 & 15.4106 & 362.28 & Jan 2005-Jan 2020 & \\
Kalfou & 10.2788 & 14.9296 & 360.61 & Jan 2005-Jan 2020 & \\
Maga & 10.8411 & 14.9472 & 349.93 & Jan 2005-Jan 2020 & \\
Yagoua & 10.3352 & 15.2095 & 334.48 & Jan 2005-Jan 2020 & \\
Mora & 11.0411 & 14.1381 & 358.28 & Jan 2005-Jan 2020 & \\
Bourrha & 10.2524 & 13.4997 & 542.23 & Jan 2005-Jan 2020 & \\
Hina & 10.3685 & 13.8436 & 544.87 & Jan 2005-Jan 2020 & \\
Mokolo & 10.7332 & 13.8303 & 558.6 & Jan 2005-Jan 2020 & \\
Dziguilao & 10.017 & 14.8 & 360.61 & Jan 2005-Jan 2020 & \\
Kaélé & 10.1 & 14.45 & 425.44 & Jan 2005-Jan 2020 & \\
\hline & & & & & \\
\hline
\end{tabular}




\subsection{Wind Speed and Standard Deviation}

In this research, the first step in the assessment of seasonal wind characteristics in FNR, is to analyze in situ measurements (3-hourly time step observed wind speed data) from 02 weather recording locations at Kousseri and Maroua and daily long-term satellite-derived data, recorded at a height of $10 \mathrm{~m}$ agl, using mean wind speeds and standard deviations. Figure 2 recapitulates monthly, annual and seasonal mean wind speeds and standard deviations using in situ and satellite measurements at Kousseri and Maroua.

It is seen in Figure 2 that the highest in situ wind speeds occur in the dry season, from November to June, while the lowest values are recorded in the rainy season between July and October. The months of August, September and October show little wind as indicated by the average rainy season wind speeds values of 2.73 and $4.63 \mathrm{~m} / \mathrm{s}$, at Maroua and Kousseri, respectively. In the meantime, it is observed is a fairly good match between in situ and satellite WS measurements in the dry season, compared to the rainy season. The variability of wind speeds (WS) is represented by the standard deviation (SD). From May to November, it is seen an equally decent match between SD values for in situ and satellite measurements. Therefore, satellite WS measurements in the dry season may suggest a more accurate prediction than that of the rainy season. Mean wind speed $v_{m}$ and standard deviation $\sigma$ are calculated as Equations (1) \& (2):

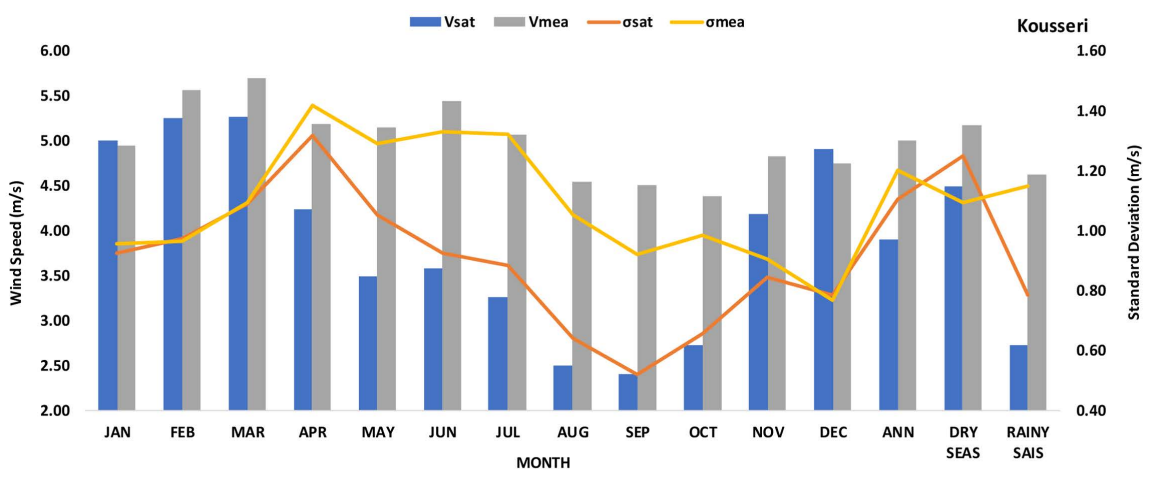

(a)

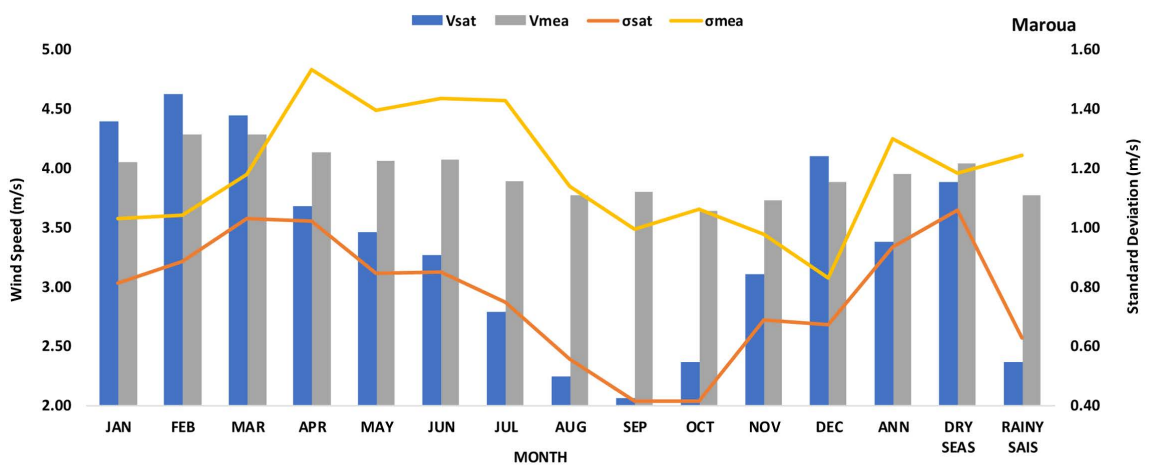

(b)

Figure 2. Monthly, annual and seasonal mean wind speeds and standard deviations using measured and satellite-derived data, at (a) Kousseri and (b) Maroua. 


$$
\begin{gathered}
v_{m}=\frac{1}{N}\left(\sum_{i=1}^{N} v_{i}\right) \\
\sigma=\left[\frac{1}{N-1} \sum_{i=1}^{n}\left(v_{i}-v_{m}\right)^{2}\right]^{1 / 2}
\end{gathered}
$$

where:

$$
\begin{aligned}
& \sigma=\text { standard deviation of the mean wind speed }[\mathrm{m} / \mathrm{s}] \\
& v_{i}=\text { wind speed }[\mathrm{m} / \mathrm{s}] \\
& N=\text { number of } \text { wind speed data. }
\end{aligned}
$$

Table 2 provides at the twenty-one selected sites, annual, dry and rainy seasons mean wind speeds, standard deviations and ambient temperatures using daily long-term satellite-derived data for the period 2005-2020, recorded at a height of $10 \mathrm{~m}$ agl. Mean wind speeds in FNR vary in the ranges of $2.99-4.32$ $\mathrm{m} / \mathrm{s}, 2.12-3.23 \mathrm{~m} / \mathrm{s}, 3.43-4.87 \mathrm{~m} / \mathrm{s}$ for yearly averages, rainy and dry seasons, respectively. It observed that the variance of streamflow occurrence in the rainy season is smaller than that of the yearly average and dry season, which may suggest a more accurate prediction. On the other hand, higher SD in the dry season present streamflow values that are widespread and may be less accurate. Mean ambient temperatures values are between $25.74^{\circ} \mathrm{C}$ and $29.67^{\circ} \mathrm{C}$. Lower temperatures are seen in the rainy season, while higher values occur in the dry season.

\subsection{Weibull Probability Density Function}

The Weibull probability density function (PDF) is used to describe the statistical distribution of wind speed. The Weibull PDF is a useful tool to characterize the wind speed and power in a given location, as well as to evaluate mean monthly, yearly and seasonal net energy production and performance wind energy systems [19] [20]. The Weibull PDF can be described by its PDF $f(V)$ and cumulative distribution function (CDF), $F(V)$ [21] using Equations (3) and (4).

$$
\begin{gathered}
f(v)=\left(\frac{k}{C}\right) \cdot\left(\frac{v}{C}\right)^{k-1} \cdot \exp \left[-\left(\frac{v}{C}\right)^{k}\right] \\
F(v)=1-\exp \left[-\left(\frac{v}{C}\right)^{k}\right]
\end{gathered}
$$

where:

$$
\begin{aligned}
& f(v)=\text { probability of observing wind speed } v \\
& v=\text { wind speed }[\mathrm{m} / \mathrm{s}] \\
& C=\text { Weibull scale parameter }[\mathrm{m} / \mathrm{s}] \\
& k=\text { Weibull shape parameter. }
\end{aligned}
$$

The determination of the two-parameter Weibull PDF requires the knowledge of the shape ( $k$, dimensionless) and scale $(C$ in $\mathrm{m} / \mathrm{s})$ parameters. Various well-established estimation methods are used for the purpose of computing Weibull parameters at a given location [22]. In this work, Weibull shape and scale parameters are computed using the energy pattern factor method (EPF). First, the energy pattern factor ( $\left.E_{p f}\right)$ [23] [24] [25] is given by Equation (5). 
Table 2. Annual, dry and rainy seasons mean wind speeds and standard deviations using satellite-derived data.

\begin{tabular}{|c|c|c|c|c|c|c|c|c|c|}
\hline $\mathbf{M}$ & Period & $\begin{array}{c}V_{m} \\
(\mathrm{~m} / \mathrm{s})\end{array}$ & $T\left({ }^{\circ} \mathrm{C}\right)$ & $\sigma(\mathrm{m} / \mathrm{s})$ & Location & Period & $V_{m}(\mathrm{~m} / \mathrm{s})$ & $T\left({ }^{\circ} \mathrm{C}\right)$ & $\sigma(\mathrm{m} / \mathrm{s})$ \\
\hline & Annual & 3.41 & 28.51 & 0.98 & & Annual & 2.99 & 28.09 & 0.89 \\
\hline \multirow[t]{3}{*}{ Bogo } & Dry & 3.93 & 29.40 & 1.11 & Gobo & Dry & 3.43 & 29.22 & 1.10 \\
\hline & Rainy & 2.36 & 26.73 & 0.63 & & Rainy & 2.12 & 25.83 & 0.63 \\
\hline & Annual & 3.30 & 28.16 & 1.04 & & Annual & 3.30 & 28.16 & 1.04 \\
\hline \multirow[t]{3}{*}{ Gazawa } & Dry & 3.82 & 29.19 & 1.18 & Kalfou & Dry & 3.82 & 29.19 & 1.18 \\
\hline & Rainy & 2.23 & 26.10 & 0.65 & & Rainy & 2.23 & 26.10 & 0.65 \\
\hline & Annual & 3.38 & 27.89 & 0.93 & & Annual & 3.41 & 28.51 & 0.98 \\
\hline \multirow[t]{3}{*}{ Maroua } & Dry & 3.88 & 28.66 & 1.06 & Maga & Dry & 3.93 & 29.40 & 1.11 \\
\hline & Rainy & 2.37 & 26.35 & 0.63 & & Rainy & 2.36 & 26.73 & 0.63 \\
\hline & Annual & 3.38 & 27.71 & 1.13 & & Annual & 3.21 & 28.45 & 0.97 \\
\hline \multirow[t]{3}{*}{ Ndoukoula } & Dry & 3.96 & 28.69 & 1.24 & Yagoua & Dry & 3.71 & 29.55 & 1.14 \\
\hline & Rainy & 2.21 & 25.74 & 0.65 & & Rainy & 2.21 & 26.23 & 0.65 \\
\hline & Annual & 4.22 & 29.19 & 1.10 & & Annual & 3.41 & 28.56 & 0.82 \\
\hline \multirow[t]{3}{*}{ Blangoua } & Dry & 4.78 & 29.26 & 1.34 & Mora & Dry & 3.86 & 29.15 & 0.99 \\
\hline & Rainy & 3.11 & 29.03 & 0.92 & & Rainy & 2.49 & 27.38 & 0.66 \\
\hline & Annual & 3.52 & 28.93 & 0.96 & & Annual & 3.34 & 26.62 & 1.14 \\
\hline \multirow[t]{3}{*}{ Darak } & Dry & 4.05 & 29.67 & 1.09 & Bourrha & Dry & 3.92 & 27.57 & 1.33 \\
\hline & Rainy & 2.45 & 27.44 & 0.65 & & Rainy & 2.18 & 24.70 & 0.69 \\
\hline & Annual & 3.90 & 29.07 & 1.04 & & Annual & 3.37 & 26.87 & 1.15 \\
\hline \multirow[t]{3}{*}{ Fotokol } & Dry & 4.46 & 29.44 & 1.22 & Hina & Dry & 3.96 & 27.84 & 1.27 \\
\hline & Rainy & 2.79 & 28.33 & 0.82 & & Rainy & 2.19 & 24.91 & 0.67 \\
\hline & Annual & 3.93 & 29.04 & 1.08 & & Annual & 3.38 & 26.79 & 0.90 \\
\hline \multirow[t]{3}{*}{ Goulfey } & Dry & 4.50 & 29.43 & 1.24 & Mokolo & Dry & 3.86 & 27.48 & 1.04 \\
\hline & Rainy & 2.78 & 28.26 & 0.79 & & Rainy & 2.40 & 25.40 & 0.67 \\
\hline & Annual & 4.32 & 29.23 & 1.08 & & Annual & 3.30 & 28.16 & 1.04 \\
\hline \multirow[t]{3}{*}{ Hile-Alifa } & Dry & 4.87 & 29.31 & 1.35 & Dziguilao & Dry & 3.82 & 29.19 & 1.18 \\
\hline & Rainy & 3.23 & 29.08 & 0.97 & & Rainy & 2.23 & 26.10 & 0.65 \\
\hline & Annual & 3.90 & 28.92 & 1.11 & & Annual & 3.38 & 27.71 & 1.13 \\
\hline \multirow[t]{3}{*}{ Kousséri } & Dry & 4.49 & 29.35 & 1.25 & Kaélé & Dry & 3.96 & 28.69 & 1.24 \\
\hline & Rainy & 2.73 & 28.08 & 0.78 & & Rainy & 2.21 & 25.74 & 0.65 \\
\hline & Annual & 3.74 & 28.98 & 1.10 & & & & & \\
\hline \multirow[t]{2}{*}{ Logone-Birni } & Dry & 4.34 & 29.63 & 1.20 & & & & & \\
\hline & Rainy & 2.55 & 27.69 & 0.71 & & & & & \\
\hline
\end{tabular}




$$
E_{p f}=\frac{\left(v^{3}\right)_{m}}{\left(v_{m}\right)^{3}}=\frac{\left(\frac{1}{n} \sum_{i=1}^{n} v_{i}^{3}\right)}{\left(\frac{1}{n} \sum_{i=1}^{n} v_{i}\right)^{3}}
$$

Then, the shape and scale parameters are computed using Equations (6) and (7).

$$
\begin{aligned}
& k=1+\frac{3.69}{\left(E_{p f}\right)^{2}} \\
& C=\frac{v_{m}}{\Gamma\left(1+\frac{1}{k}\right)}
\end{aligned}
$$

\subsection{Statistical Indicators for Accuracy Evaluation}

To assess the accuracy level for the goodness-of-fit tests of satellite-derived data, five reliable statistical indicators have been used to compare measured 3-hourly time step observed wind speed data and daily long-term satellite-derived data. These statistical indicators are presented using Equations (8) to (12) as follows:

1) Mean Bias Error [26] [27]:

$$
\operatorname{MBE}=\left[\frac{1}{N} \sum_{i=1}^{N}\left(S_{i}-M_{i}\right)^{2}\right]^{1 / 2}
$$

2) Root mean square error (RMSE) [28] [29]:

$$
\operatorname{RMSE}=\left[\frac{1}{N} \sum_{i=1}^{N}\left(S_{i}-M_{i}\right)^{2}\right]^{1 / 2}
$$

3) Relative root mean square error (RRMSE) [19] [30]:

$$
\text { RRMSE }=\frac{\left[\frac{1}{N} \sum_{i=1}^{N}\left(S_{i}-M_{i}\right)^{2}\right]^{1 / 2}}{\frac{1}{N} \sum_{i=1}^{N} M_{i}} \times 100
$$

4) Coefficient of determination $\left(R^{2}\right)[19][31]$ :

$$
\mathrm{R}^{2}=1-\frac{\sum_{i=1}^{N}\left(S_{i}-M_{i}\right)^{2}}{\sum_{i=1}^{N}\left(M_{i}-\overline{S_{i}}\right)^{2}}
$$

5) Index of Agreement (IOA) [19] [32]:

$$
\mathrm{IOA}=1-\frac{\overline{S_{i}}-\overline{M_{i}}}{\sum_{i=1}^{N}\left(\left|S_{i}-\overline{M_{i}}\right|+\left|M_{i}-\overline{M_{i}}\right|\right)^{2}}
$$

where:

$M_{i}: i^{\text {th }}$ Cumulative frequency distribution (CFD) of measured WS;

$S_{i}: i^{\text {th }}$ CFD of satellite-derived WS;

$N$ : Number of non-zero WS data points,

$\overline{M_{i}}:$ Mean value of $M_{i}$; 
$\overline{S_{i}}:$ Mean value of $S_{i}$.

\subsection{Extrapolation of Wind Speed}

The wind speed data were collected at a height of $10 \mathrm{~m}$ agl. In this study, six wind turbines (WT), with a hub height of $30 \mathrm{~m}$ each, are chosen. Therefore, WS data obtained at $10 \mathrm{~m}$ height agl, must be extrapolated to the relevant WT hub height. The Weibull PDF is used to extrapolate WS values at $30 \mathrm{~m}$ height. The Weibull scale and shape parameters at $10 \mathrm{~m}$ height agl are related to that of the WT hub height [33] [34] by Equations (13) and (14).

$$
\begin{gathered}
C_{z}=C_{10} *\left(\frac{z}{z_{10}}\right)^{n} \\
k_{z}=\frac{k_{10}}{1-0.00881 \ln (z / 10)}
\end{gathered}
$$

The power law exponent $\mathrm{n}$ is given by Equation (15).

$$
n=\left[0.37-0.088 \ln \left(C_{10}\right)\right]
$$

where, $z$ and $z_{10}$ are in meters, Weibull $C_{10}$ and $k_{10}$ parameters are determined at $10 \mathrm{~m}$ height agl.

\subsection{Mean Wind Power Density and Energy Density}

Expressed in watts per square meter $\left(\mathrm{W} / \mathrm{m}^{2}\right)$, wind power density $(P(v))$ considers the wind speed frequency distribution of a given location and the power of wind which is proportional to the air density and the cube of the wind speed. The power of wind $(P(v))$ can be estimated using Equation (16).

$$
P(v)=\frac{1}{2} \rho A v^{3}
$$

The mean wind power density $\left(p_{D}\right)$ based on the Weibull probability density function can be calculated using Equation (17).

$$
p_{D}=\frac{P(v)}{A}=\frac{1}{2} \rho C^{3} \Gamma\left(1+\frac{3}{k}\right)
$$

The mean energy density $\left(E_{D}\right)$ over a period of time $T$ is expressed as Equation (18).

$$
E_{D}=\frac{1}{2} \rho C^{3} \Gamma\left(1+\frac{3}{k}\right) T
$$

where:

$$
\begin{aligned}
& \rho=\text { air density at the site; } \\
& A=\text { swept area of the rotor blades }\left[\mathrm{m}^{2}\right] .
\end{aligned}
$$

The air density (in kilograms per cubic meter) at a given site is computed as the mass of a quantity of air (in $\mathrm{kg}$ ) divided by its volume (in cubic meter). It depends on elevation and temperature above sea level and can be computed [35] using Equation (19). 


$$
\rho_{a}=\frac{353.049}{T} \mathrm{e}^{\left(-0.034 \frac{Z}{T}\right)}
$$

where:

$$
\begin{aligned}
Z & =\text { elevation }(\mathrm{m}) ; \\
T & =\text { temperature at the considered site }\left({ }^{\circ} \mathrm{K}\right) .
\end{aligned}
$$

\subsection{Wind Turbine and Electric Pumping Systems}

Six wind turbines (WT) from different manufacturers are considered. For uniformity in the comparison, wind machines of $10 \mathrm{~kW}$ size and hub height of 30 $\mathrm{m}$ each, are chosen. The six WT are represented by $\mathrm{WT}_{1}, \mathrm{WT}_{2}, \mathrm{WT}_{3}, \mathrm{WT}_{4}, \mathrm{WT}_{5}$ and $\mathrm{WT}_{6}$, to avoid the use of registered names and trademarks. Table 3 provides the technical characteristics of the six selected WT, which are relevant to the present study. These WT can be subdivided into three groups. The first group covers cut-in wind speed (WS) of $2 \mathrm{~m} / \mathrm{s}\left(\mathrm{WT}_{1}\right.$ and $\left.\mathrm{WT}_{2}\right), 2.5 \mathrm{~m} / \mathrm{s}\left(\mathrm{WT}_{3}\right)$ and 3 $\mathrm{m} / \mathrm{s}\left(\mathrm{WT}_{4}, \mathrm{WT}_{5}\right.$ and $\left.\mathrm{WT}_{6}\right)$. The second group comprises rated WS of $10 \mathrm{~m} / \mathrm{s}$ $\left(\mathrm{WT}_{1}\right.$ and $\left.\mathrm{WT}_{3}\right), 11 \mathrm{~m} / \mathrm{s}\left(\mathrm{WT}_{2}, \mathrm{WT}_{4}\right.$ and $\left.\mathrm{WT}_{5}\right)$ and $12 \mathrm{~m} / \mathrm{s}\left(\mathrm{WT}_{6}\right)$. The third group includes cut-out WS of $25 \mathrm{~m} / \mathrm{s}\left(\mathrm{WT}_{1}, \mathrm{WT}_{2}, \mathrm{WT}_{3}\right.$ and $\left.\mathrm{WT}_{4}\right)$ and $30 \mathrm{~m} / \mathrm{s}$ $\left(\mathrm{WT}_{5}\right.$ and $\left.\mathrm{WT}_{6}\right)$. These WT are designed for low wind power density regimes, which are relevant to FNR. For the sake of simplicity, a $50 \mathrm{~m}$ pumping head was considered for volumetric flow rates calculations at the twenty-one selected locations. It should be noted that, although a $50 \mathrm{~m}$ pumping head is considered to calculate volumetric flow rates, a different pumping head can be considered, since the volumetric flow rate of water is inversely proportional to the pumping head.

\subsection{Power Curve Model and Capacity Factor}

The typical power curve of a 10-kW pitch-controlled WT is shown in Figure 3(a), while the power curves using the six selected pitch-controlled WT of $10 \mathrm{~kW}$ rated capacity are plotted in Figure 3(b). As a result of the pitch regulated systems, the voltage of the electricity at which pitch-controlled WT generate power at WS above their rated levels, does not decrease [36]. Four different zones are observed in this curve (Figure 3(a)). For WS in the range of zero to $V_{I}$ (cut-in WS),

Table 3. Characteristics of the selected wind turbines.

\begin{tabular}{lcccccc}
\hline \multicolumn{1}{c}{ Characteristics } & $\mathrm{WT}_{1}$ & $\mathrm{WT}_{2}$ & $\mathrm{WT}_{3}$ & $\mathrm{WT}_{4}$ & $\mathrm{WT}_{5}$ & $\mathrm{WT}_{6}$ \\
\hline Hub height $(\mathrm{m})$ & 30 & 30 & 30 & 30 & 30 & 30 \\
Rated power $P_{R}(\mathrm{~kW})$ & 10 & 10 & 10 & 10 & 10 & 10 \\
Rotor diameter $(\mathrm{m})$ & 10 & 10 & 10 & 10 & 10 & 10 \\
Cut-in wind speed $V_{C}(\mathrm{~m} / \mathrm{s})$ & 2 & 2 & 2.5 & 3 & 3 & 3 \\
Rated wind speed $V_{R}(\mathrm{~m} / \mathrm{s})$ & 10 & 11 & 10 & 11 & 11 & 12 \\
Cut-off wind speed $V_{F}(\mathrm{~m} / \mathrm{s})$ & 25 & 25 & 25 & 25 & 30 & 30 \\
Price $(\mathrm{USD} / \mathrm{kW})$ & 2600 & 2600 & 2600 & 2600 & 2600 & 2600 \\
Price $\left(100{ }^{*} \mathrm{XAF} / \mathrm{kW}\right)$ & 1560 & 1560 & 1560 & 1560 & 1560 & 1560 \\
\hline
\end{tabular}




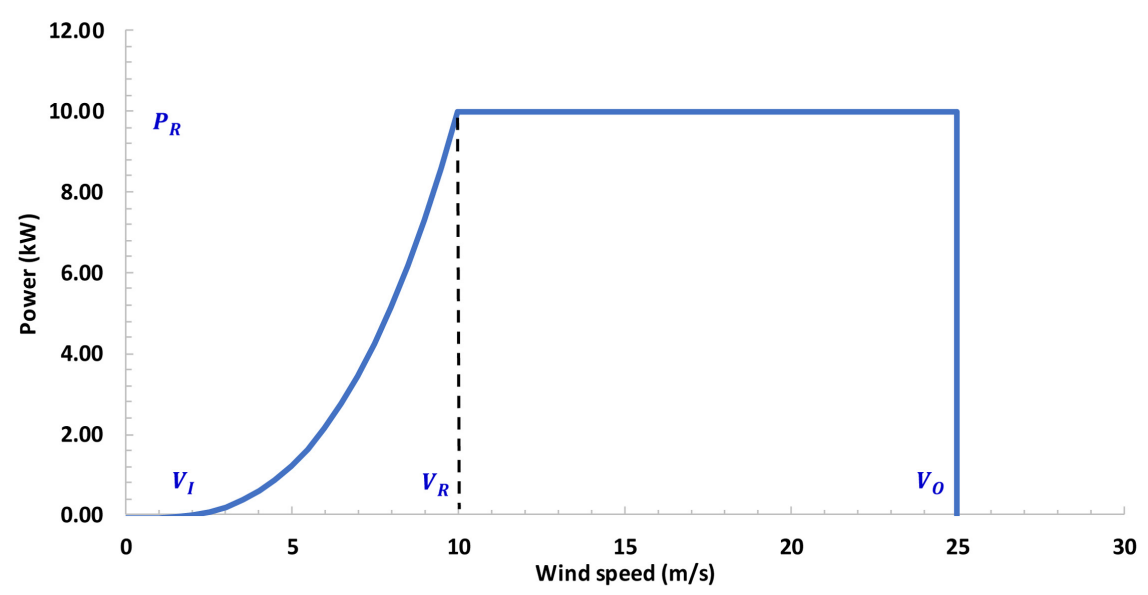

(a)

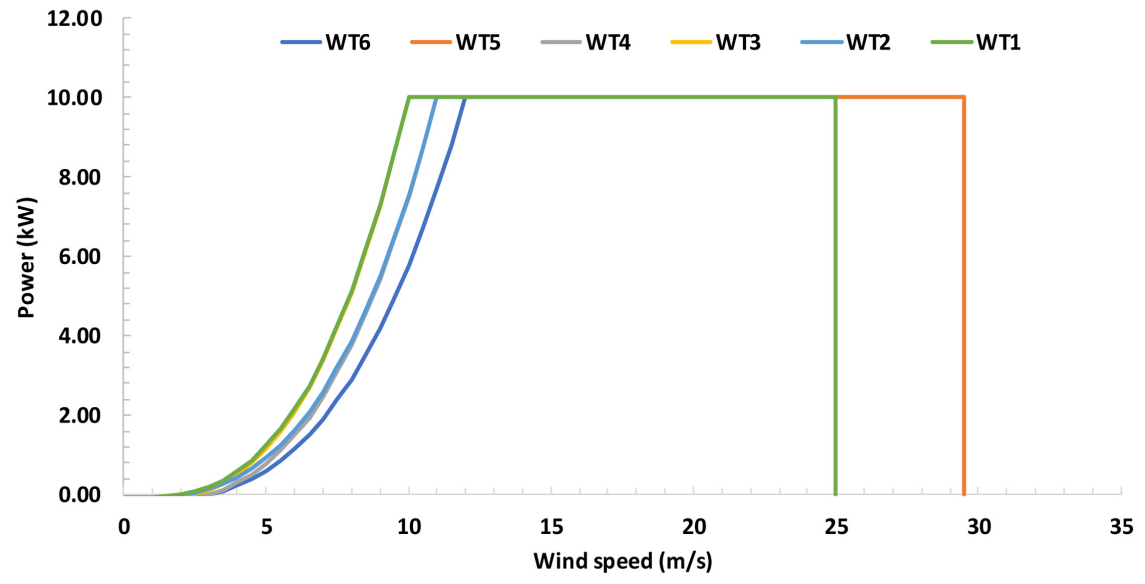

(b)

Figure 3. Power curve of (a) a typical pitch-controlled WT, (b) the selected wind turbine.

the WT does not yield any output. Between the cut-in and rated WS ( $V_{I}$ to $V_{R}$ ), the power increases with the WS. In the present analysis, it is assumed that the power output curve shows a quadratic power shape. From the rated WS $\left(V_{R}\right)$ to the cut-out WS $\left(V_{O}\right)$, the WT yields a constant output at the rated power $\left(P_{R}\right)$, regardless of WS variations. For WS higher than $V_{O}$, there is no output and the system shuts down the WT for to safety reasons.

The model of wind power curve used in this research considers a piecewise output function of the power output $\left(P_{e}\right)$, given the cut-in wind speed $\left(v_{c}\right)$, rated wind speed $\left(V_{R}\right)$, cut-off wind speed $\left(V_{F}\right)$ and rated electrical power $\left(P_{e R}\right)$. All these speeds and power are computed using the parabolic law [37], as a combination of Equation (20).

$$
P_{e}=\left\{\begin{array}{lc}
0 & \left(v<v_{c}\right) \\
P_{e R} \frac{v^{k}-v_{c}^{k}}{v_{R}^{k}-v_{c}^{k}} & v_{c} \leq v \leq v_{R} \\
P_{e R} & v_{R} \leq v \leq v_{F} \\
0 & \left(v_{F}<v\right)
\end{array}\right.
$$


The average power output $\left(P_{e, a v e}\right)$ of the WT, based on the Weibull PDF, can be computed using Equation (21).

$$
P_{e, a v e}=P_{e R}\left\{\frac{\mathrm{e}^{-\left(\frac{v_{c}}{C}\right)^{k}}-\mathrm{e}^{-\left(\frac{v_{R}}{C}\right)^{k}}}{\left(\frac{v_{R}}{C}\right)^{k}-\left(\frac{v_{c}}{C}\right)^{k}}-\mathrm{e}^{-\left(\frac{v_{F}}{C}\right)^{k}}\right\}
$$

The ratio of the average power output $\left(P_{e, a v e}\right)$ to the rated electrical power $\left(P_{e R}\right)$ of the WT is known as the capacity factor CF. CF can thus be expressed [38] as Equation (22).

$$
\mathrm{CF}=\left\{\frac{\mathrm{e}^{-\left(\frac{v_{c}}{C}\right)^{k}}-\mathrm{e}^{-\left(\frac{v_{R}}{C}\right)^{k}}}{\left(\frac{v_{R}}{C}\right)^{k}-\left(\frac{v_{c}}{C}\right)^{k}}-\mathrm{e}^{-\left(\frac{v_{F}}{C}\right)^{k}}\right\}
$$

\subsection{Water Pumping Capacity}

The water pumping capacity rate $\left(F_{w}\right)$ is related to the net hydraulic power output $\left(P_{\text {out }}\right)$ and the efficiency of the pump. To determine a volume of water $V_{w}\left(\mathrm{~m}^{3}\right)$, the net hydraulic power output $\left(P_{\text {out }}\right)$ and volumetric flow rate of water $\left(Q_{w}\right)$ are computed [39] using Equations (23) and (24).

$$
\begin{gathered}
P_{\text {out }}=\frac{\rho_{w} \cdot g \cdot V_{w} \cdot H}{\eta T}=\frac{\rho_{w} \cdot g \cdot Q_{w} \cdot H}{\eta} \\
Q_{w}=\frac{\eta \cdot P_{\text {out }}}{\rho_{w} \cdot g \cdot H}
\end{gathered}
$$

where:

$$
\begin{aligned}
& Q_{w}=\text { volumetric flow rate }\left[\mathrm{m}^{3} / \mathrm{day}\right] \\
& \rho_{w}=\text { water density }\left[\mathrm{kg} / \mathrm{m}^{3}\right] ; \\
& g=\text { acceleration due to gravity }\left[\mathrm{m} / \mathrm{s}^{2}\right] ; \\
& H=\text { pump head }[\mathrm{m}] ; \\
& \eta=\text { system efficiency. }
\end{aligned}
$$

With the pump efficiency $\left(\eta_{\text {PUMP }}=62 \%\right.$ ) considered, the water pumping capacity rate $\left(F_{w}\right)$ is expressed as Equation (25).

$$
F_{w}=367 \times \eta_{\text {PUMP }} \cdot P_{\text {out }}
$$

\subsection{Costs Analysis}

The water pumping capacity rate $\left(F_{w}\right)$ is related to the net hydraulic power output $\left(P_{\text {out }}\right)$ and the efficiency of the pump. To determine a volume of water $V_{w}\left(\mathrm{~m}^{3}\right)$, the Costs analysis are performed to evaluate the costs of energy (COE) and costs of water (COW) produced, using the present value of costs (PVC) of energy produced per year [40]:

$$
\mathrm{PVC}=I+C_{\text {om }}\left(\frac{1+i}{r-i}\right) *\left(1-\left(\frac{1+i}{1+r}\right)^{n}\right)-S\left(\frac{1+i}{1+r}\right)^{n}
$$


With the following assumptions:

- I is the investment cost, which includes WT price in addition to $20 \%$ for civil works and other connections;

- Average specific WT cost per kW is USD 2600, for WT rated power less than $20 \mathrm{~kW}[41]$;

- $n$ is the useful lifetime of WT in years (20 years);

- $i_{0}$ is the nominal interest rate $(16 \%)$;

- $S$ is the scrap value (10\% of WT price);

- $i$ is the inflation rate $(3.6 \%)$;

- $C_{o m}$ is the operation and maintenance costs (7.5\% of the investment cost).

The discount rate $(r)$ is determined [42] using Equation (27).

$$
r=\frac{i_{0}-i}{1+i}
$$

The total energy output ( $E_{W T}$ ) over WT lifetime (in kilowatt-hour) is computed using CDF of wind speeds at which WT produce energy $(A)$, rated power of the WT, capacity factor CF and WT lifetime working hours. $E_{W T}$ is computed as Equation (28).

$$
E_{W}=8760 * A * n * P_{R} * C_{f}
$$

The costs of energy (COE) per unit kWh and costs of water (COW) per unit $\mathrm{m}^{3}$ are estimated using Equations (29) and (30).

$$
\begin{aligned}
\mathrm{COE} & =\frac{\mathrm{PVC}}{E_{W}} \\
\mathrm{COW} & =\frac{\mathrm{PVC}}{n \cdot V_{w}}
\end{aligned}
$$

The annual volume of water $V_{w}\left(\mathrm{~m}^{3} /\right.$ year $)$ produced is determined using Equation (31).

$$
V_{w}=\frac{\eta \cdot E_{w}}{n \cdot \rho_{w} \cdot g \cdot H}
$$

\section{Results and Discussion}

\subsection{Wind Characteristics}

\subsubsection{Weibull PDF and CDF at $10 \mathrm{~m}$ Height Agl (Measured vs Satellite Data)}

Figure 4 and Figure 5 show monthly average PDF at $10 \mathrm{~m}$ height agl, respectively at Kousseri and Maroua using both measured and satellite-derived data, while Figure 6 and Figure 7 present the corresponding values for Weibull CDF plots. The comparison of Weibull PDF plots using measured and satellite data show similar trends for the dry season, both at Kousseri and Maroua, with similar probability of meeting different wind speeds. On the other hand, Weibull PDF plots using measured data display higher probability (around 0.31 ) of meeting low wind speeds (around $1.5 \mathrm{~m} / \mathrm{s}$ ) for the rainy season in Kousseri, while lower probability (around 0.15 ) are observed for the corresponding wind speeds using satellite data. 


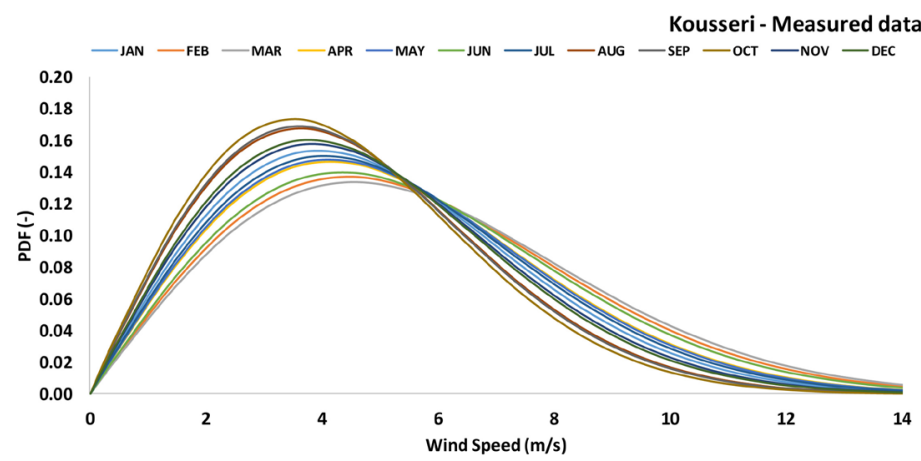

(a)

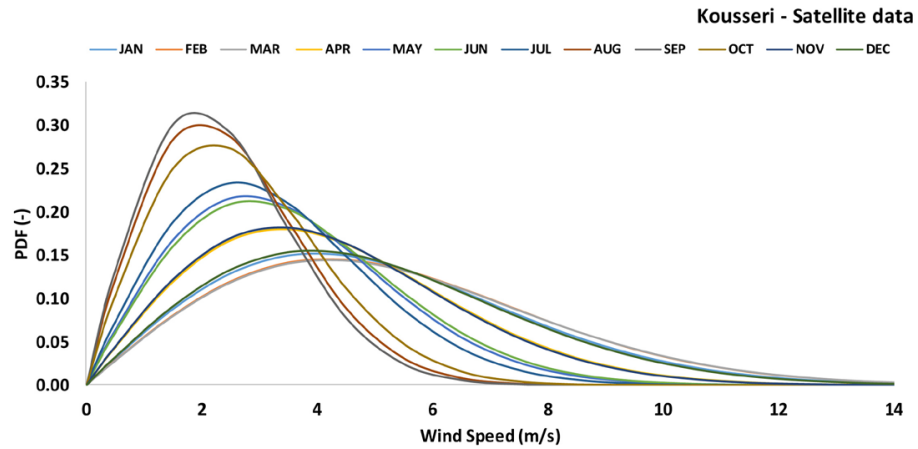

(b)

Figure 4. Monthly average PDF at $10 \mathrm{~m}$ height agl at Kousseri using (a) measured data and (b) satellite-derived data.

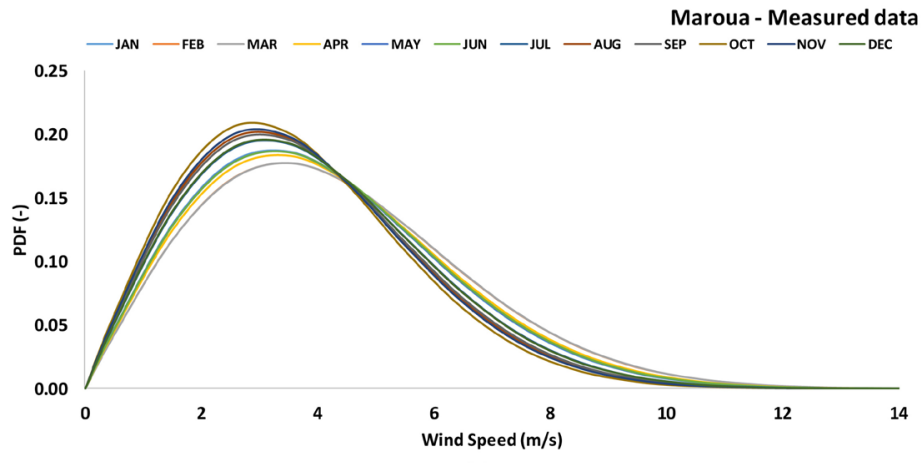

(a)

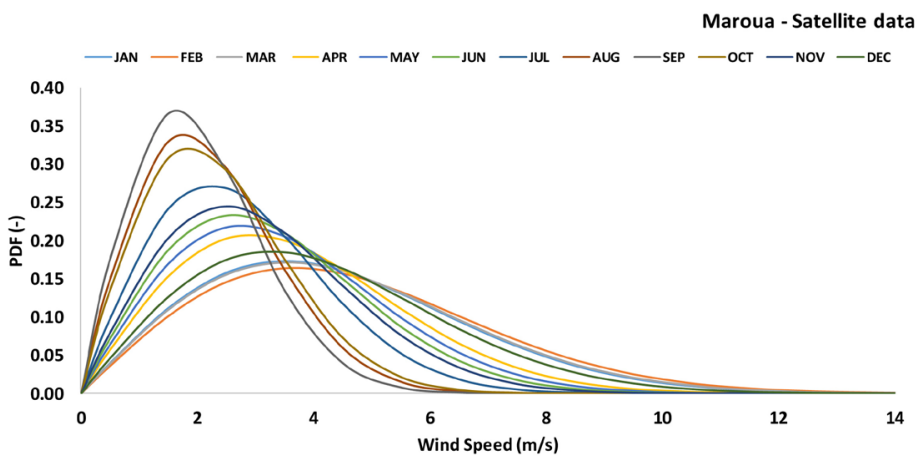

(b)

Figure 5. Monthly average PDF at $10 \mathrm{~m}$ height agl at Maroua using (a) measured data and (b) satellite-derived data. 


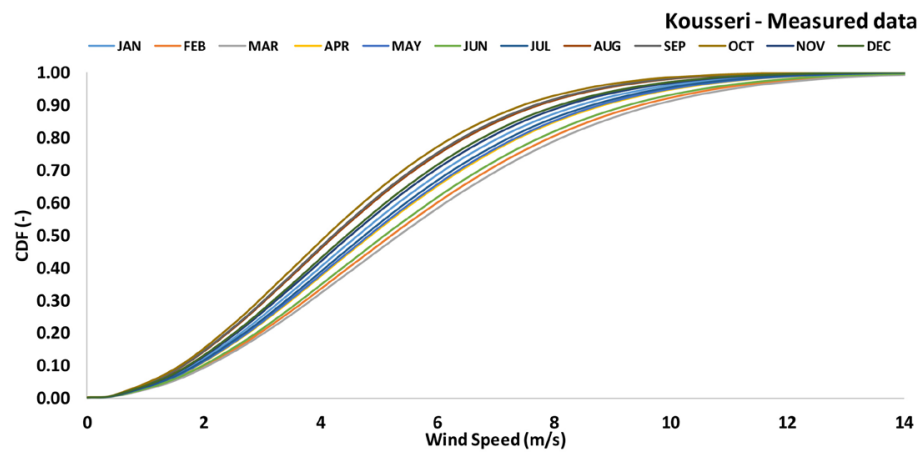

(a)

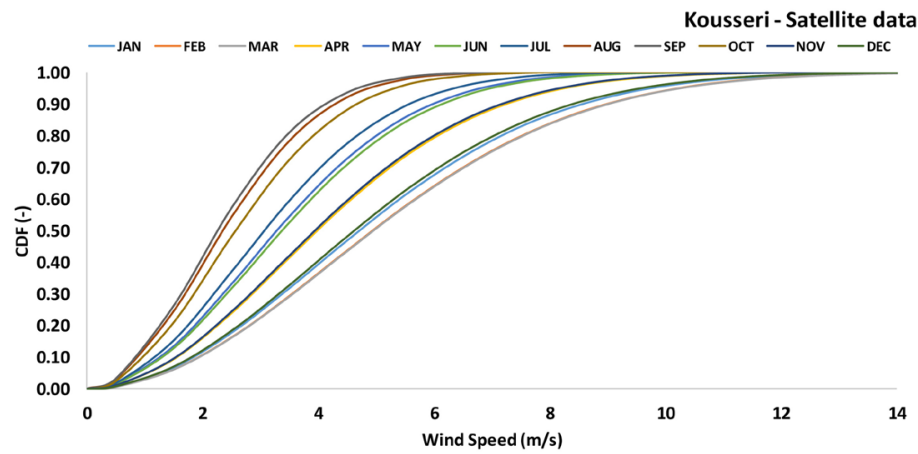

(b)

Figure 6. Monthly average CDF at $10 \mathrm{~m}$ height agl at Kousseri using (a) measured data and (b) satellite-derived data.

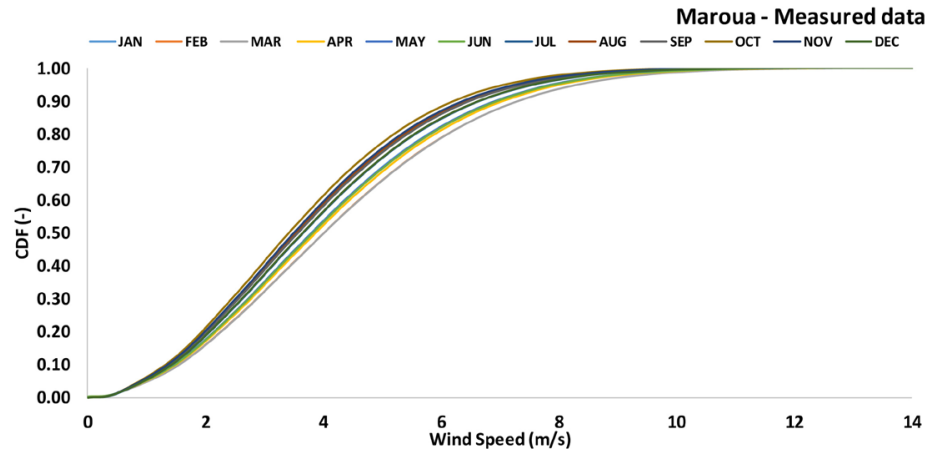

(a)

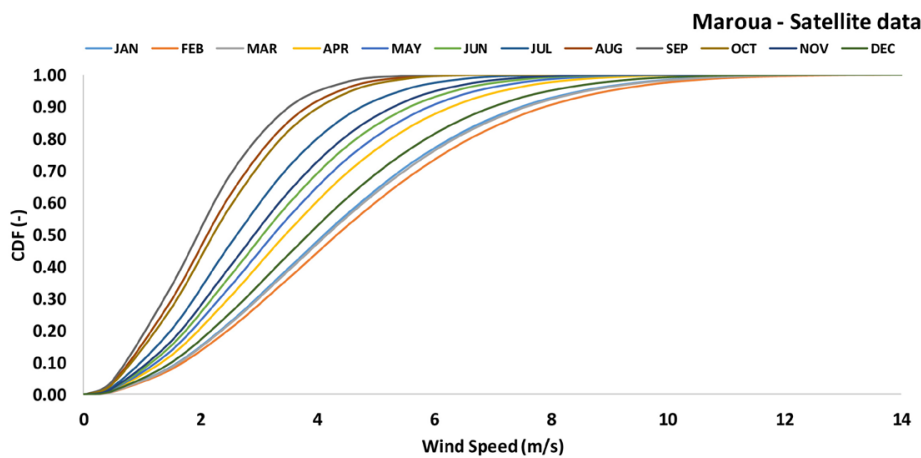

(b)

Figure 7. Monthly average CDF at $10 \mathrm{~m}$ height agl at Maroua using (a) measured data and (b) satellite-derived data. 
At the site of Maroua, it is observed under the same conditions, lower probability (around 0.15) using measured data and higher probability (around 0.31) using measured data. Statistical indicators for the accuracy of satellite-derived WS at Kousseri and Maroua are displayed in Table 4. Weibull CDF values provided data for the statistical analysis and comparison between measured and satellite-derived data.

\subsubsection{Statistical Indicators for the Accuracy of Satellite-Derived WS at Kousseri and Maroua}

Table 4 shows different values obtained using the five statistical indicators for the accuracy of satellite-derived wind speed at Kousseri and Maroua.

The $\mathrm{MBE}$ predicts overestimations $(\mathrm{MBE}<0)$ or underestimations $(\mathrm{MBE}>0)$ of the satellite-derived wind speed values. On average, MBE values are slightly overestimated at Kousseri and Maroua. MBE values at Kousseri are 0.037, 0.023 and 0.063 , respectively for annual, dry and rainy seasons periods, while they are 0.019 (annual), 0.005 (dry season) and 0.047 (rainy season) at Maroua.

The RMSE provides the deviation between the values achieved by satellitederived data and those of in-situ wind measurements data. The RMSE has always a positive value. RMSE values are that are close to zero, can be considered successful forecasts. RMSE values for annual, dry and rainy seasons periods, give 0.069 , 0.042 and 0.129 at Kousseri, and 0.040, 0.011 and 0.105 at Maroua, in that order.

Table 4. Statistical indicators for the accuracy of satellite-derived wind speed at Kousseri and Maroua.

\begin{tabular}{|c|c|c|c|c|c|c|c|c|c|c|}
\hline \multirow{2}{*}{ PERIOD } & \multicolumn{5}{|c|}{ Kousseri } & \multicolumn{5}{|c|}{ Maroua } \\
\hline & MBE & RMSE & RMSE & $\mathbf{R}^{2}$ & IOA & MBE & RMSE & RRMSE & $\mathbf{R}^{2}$ & IOA \\
\hline JAN & -0.002 & 0.003 & $0.41 \%$ & 0.832 & 1.000 & -0.011 & 0.022 & $2.65 \%$ & 0.847 & 1.000 \\
\hline FEB & 0.010 & 0.018 & $2.23 \%$ & 0.822 & 0.999 & -0.012 & 0.022 & $2.68 \%$ & 0.844 & 1.000 \\
\hline MAR & 0.014 & 0.024 & $3.07 \%$ & 0.820 & 0.999 & -0.005 & 0.010 & $1.24 \%$ & 0.842 & 1.000 \\
\hline APR & 0.032 & 0.058 & $7.01 \%$ & 0.823 & 0.998 & 0.015 & 0.030 & $3.53 \%$ & 0.838 & 0.999 \\
\hline MAY & 0.055 & 0.105 & $12.28 \%$ & 0.816 & 0.996 & 0.020 & 0.041 & $4.79 \%$ & 0.836 & 0.998 \\
\hline JUN & 0.062 & 0.115 & $13.44 \%$ & 0.812 & 0.995 & 0.027 & 0.056 & $6.47 \%$ & 0.833 & 0.998 \\
\hline JUL & 0.060 & 0.116 & $13.49 \%$ & 0.813 & 0.995 & 0.037 & 0.080 & $9.09 \%$ & 0.826 & 0.997 \\
\hline AUG & 0.068 & 0.141 & $15.89 \%$ & 0.804 & 0.993 & 0.051 & 0.115 & $12.79 \%$ & 0.807 & 0.995 \\
\hline SEP & 0.070 & 0.147 & $16.46 \%$ & 0.800 & 0.993 & 0.058 & 0.132 & $14.61 \%$ & 0.795 & 0.994 \\
\hline OCT & 0.055 & 0.115 & $13.07 \%$ & 0.814 & 0.995 & 0.043 & 0.097 & $10.86 \%$ & 0.815 & 0.996 \\
\hline $\mathrm{NOV}$ & 0.021 & 0.039 & $4.74 \%$ & 0.830 & 0.998 & 0.021 & 0.045 & $5.15 \%$ & 0.837 & 0.998 \\
\hline DEC & -0.006 & 0.010 & $1.24 \%$ & 0.836 & 1.000 & -0.007 & 0.014 & $1.72 \%$ & 0.848 & 1.001 \\
\hline ANNUAL & 0.037 & 0.069 & $8.20 \%$ & 0.823 & 0.997 & 0.019 & 0.040 & $4.65 \%$ & 0.837 & 0.998 \\
\hline $\begin{array}{c}\text { DRY } \\
\text { SEASON }\end{array}$ & 0.023 & 0.042 & $5.07 \%$ & 0.825 & 0.998 & 0.005 & 0.011 & $1.27 \%$ & 0.842 & 1.000 \\
\hline $\begin{array}{l}\text { RAINY } \\
\text { SEASON }\end{array}$ & 0.063 & 0.129 & $14.69 \%$ & 0.809 & 0.994 & 0.047 & 0.105 & $11.80 \%$ & 0.813 & 0.995 \\
\hline
\end{tabular}


The RRMSE is calculated by dividing the RMSE to the average of CFD of measured WS. For RRMSE values that are less than 10\%, the precision is excellent, while the precision is good for RRMSE values in the range of $10 \%-20 \%$. RRMSE values at Kousseri and Maroua are, on average, less than $10 \%$ for annual and dry season periods, while these values are in the range of $10 \%-20 \%$ for the rainy season. The accuracy of satellite-derived data can be defined as excellent for the yearly average and dry season, while it can be rated as good for the rainy season, at both locations.

$\mathrm{R}^{2}$ gives the linear relationship between satellite-derived and in-situ wind measurements data. $\mathrm{R}^{2}$ is supposed to be a perfect distribution model if it is characterized by a value equal to one, which represents a better fit using satellite-derived data. $\mathrm{R}^{2}$ values are in the range of $0.825-0.809$ at Kousseri and between 0.813 - 0.842 at Maroua. These values are sufficiently high enough to represent a better fit using satellite-derived data.

IOA is used to evaluate the accuracy of satellite-derived data to in-situ wind measurements data. IOA values are in the range of 0 and 1. IOA values directly above 0.5 indicate efficiency in the forecast. IOA values are $0.997,0.998$, and 0.994 at Kousseri and $0.998,1.000$ and 0.995 at Maroua, respectively for the yearly average, dry and rainy seasons. As a result, IOA values show high efficiency in the use of satellite-derived data. The analysis of statistical indicators shows an accuracy level in the range of excellent to good, to test the goodness-of-fit of satellite-derived data. Therefore, satellite WS are found to be a good fit with high correlation at both locations.

\subsubsection{Wind Characteristics at $10 \mathrm{~m}$ Height Agl for the Twenty-One Locations}

Figure 8 presents seasonal average PDF at $10 \mathrm{~m}$ height agl for the twenty-one selected locations. Dry season average PDF (Figure 8(a)) displays lower percentage probability, with a larger range of speeds, while rainy season average PDF (Figure 8(b)) shows higher percentage probability, with a narrower range of WS. Table 5 presents seasonal variation of wind characteristics at $10 \mathrm{~m}$ height agl for the twenty-one locations. Seasonal values of $\mathrm{k}$ range from 2.99 to 3.54 and indicate sharper peak and narrow distribution of WS. On the other hand, scale parameters at the twenty-one selected locations display values in the range of 3.83 $5.42 \mathrm{~m} / \mathrm{s}$ for dry season and between 2.37 and $3.61 \mathrm{~m} / \mathrm{s}$ for rainy season. The shape parameter describes the size of the width of WS distribution, while the scale parameter expresses the magnitude of WS. Lower $\mathrm{k}$ values indicate a tendency of WS to vary over a wide range around averages, whereas higher k values show a propensity of WS to stay within a narrow range. Mean WS values are within $3.43-4.87 \mathrm{~m} / \mathrm{s}$ and $2.12-3.23 \mathrm{~m} / \mathrm{s}$ ranges, respectively for dry and rainy seasons.

Seasonal values of air density fluctuate between 1.10 and $1.13 \mathrm{~kg} / \mathrm{m}^{3}$. Wind power density values vary between 7.35 and $26.05 \mathrm{~W} / \mathrm{m}^{2}$ for rainy season while the corresponding values for dry season are in the range of $31.10-87.77 \mathrm{~W} / \mathrm{m}^{2}$. 


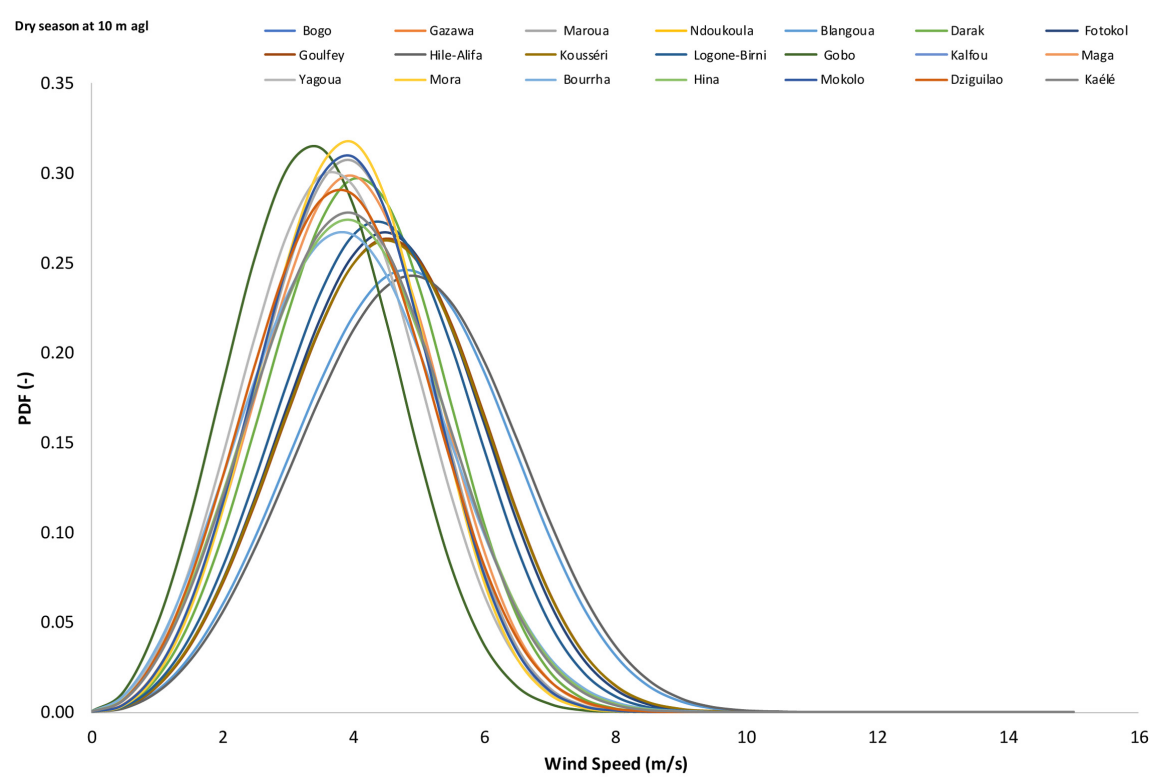

(a)

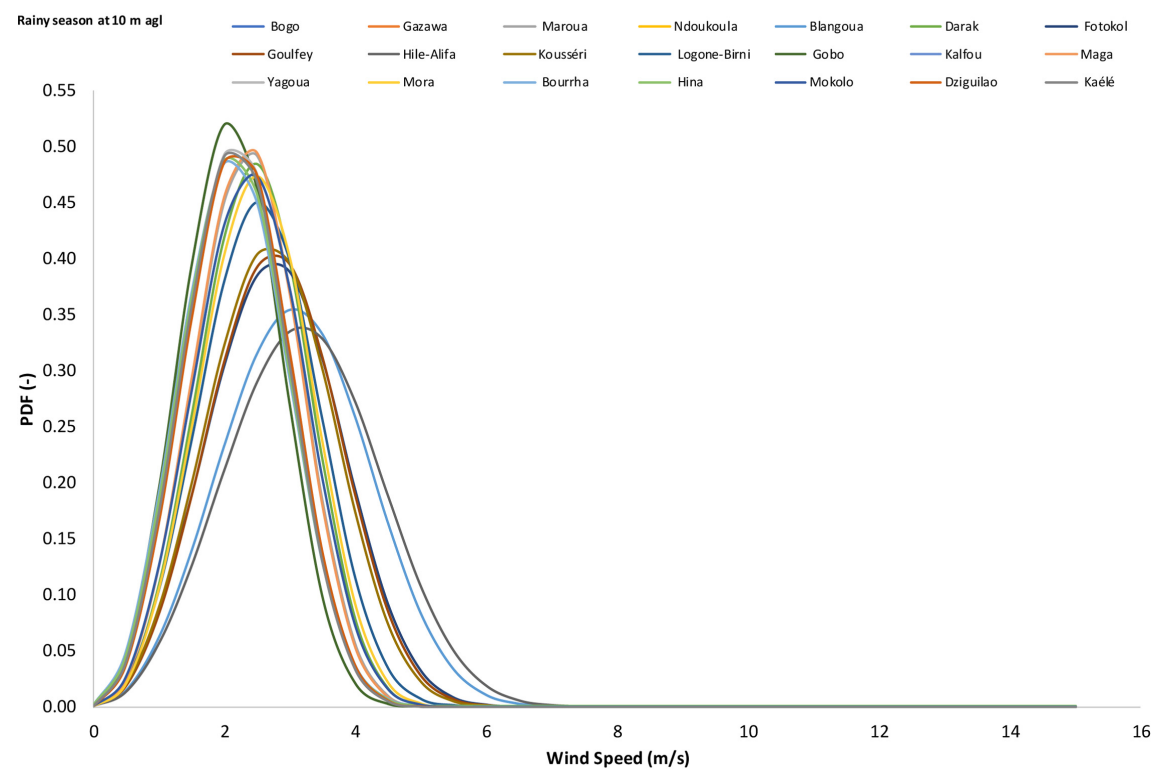

(b)

Figure 8. Seasonal average PDF at $10 \mathrm{~m}$ height agl for the twenty-one selected locations during (a) dry season (b) rainy season.

Mean energy density values range from 0.75 to $2.06 \mathrm{kWh} / \mathrm{m}^{2} /$ day and from 0.18 to $0.63 \mathrm{kWh} / \mathrm{m}^{2} /$ day $\mathrm{m} / \mathrm{s}$, respectively for dry and rainy seasons.

\subsubsection{Wind Characteristics at WT's Hub Height}

Figure 9 illustrates seasonal average PDF at $30 \mathrm{~m}$ height agl for the twenty-one selected locations. As previously described, dry season average PDF (Figure 9(a)) displays lower percentage probability, with a larger range of speeds, whereas rainy season average PDF (Figure 9 (b)) shows higher percentage probability, with a narrower range of WS. 


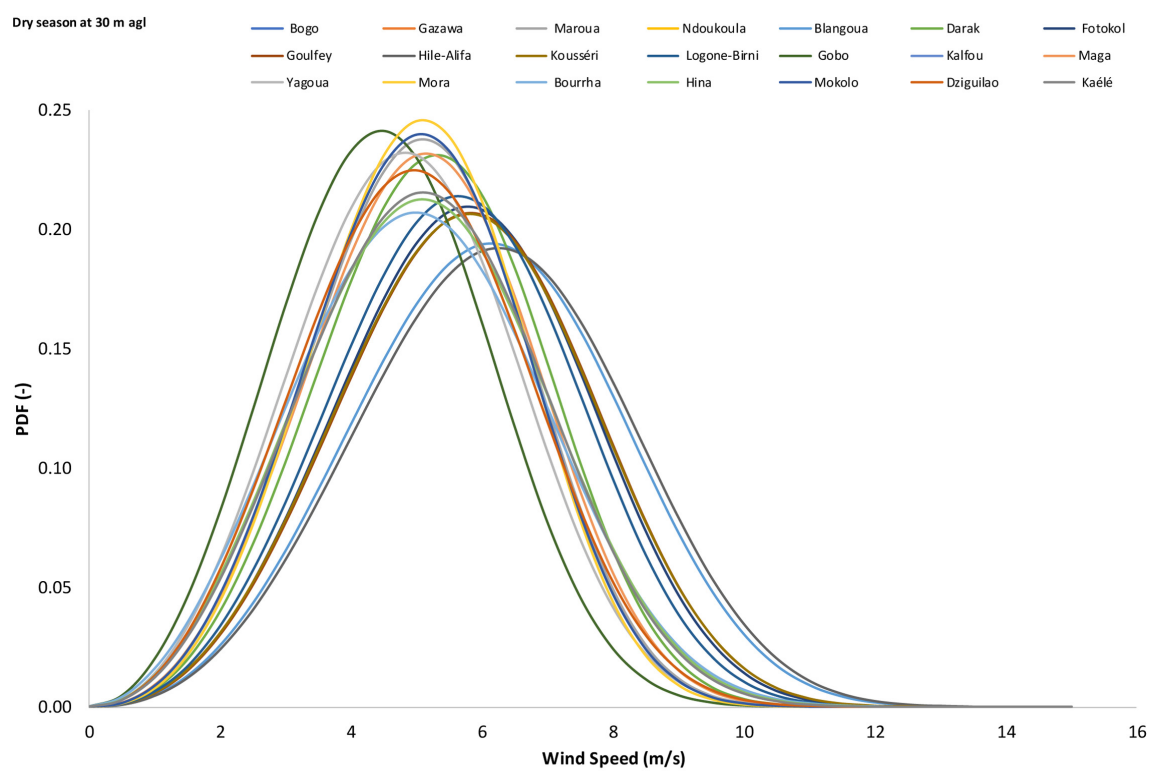

(a)

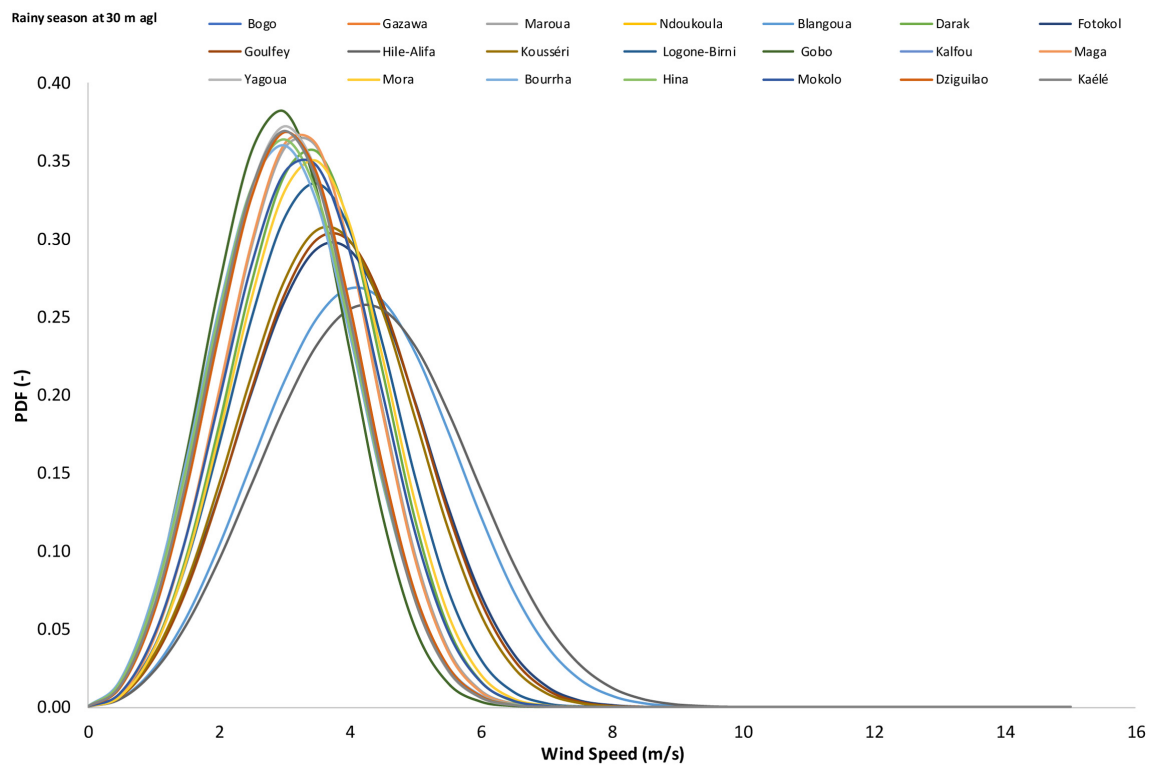

(b)

Figure 9. Seasonal average PDF at $30 \mathrm{~m}$ height agl for the twenty-one selected locations during (a) dry season (b) rainy season.

Table 6 proposes seasonal variation of wind characteristics at $30 \mathrm{~m}$ height agl for the twenty-one locations. Mean values of air density, Weibull parameters, wind speeds, power and energy densities are adjusted to reflect the $30 \mathrm{~m}$-hub height tower. Seasonal values of $\mathrm{k}$ range from 3.02 to 3.58 and express sharper peak and narrow distribution of WS. On the other hand, scale parameters show values between 5.05 and $6.91 \mathrm{~m} / \mathrm{s}$ for dry season and in the range of $3.27-4.78 \mathrm{~m} / \mathrm{s}$ for rainy season. At $30 \mathrm{~m}$ height agl, mean WS values are between 4.52 and $6.21 \mathrm{~m} / \mathrm{s}$ for dry season and vary from 2.93 to $4.28 \mathrm{~m} / \mathrm{s}$ for rainy season. Wind power density values vary between 70.88 and $176.96 \mathrm{~W} / \mathrm{m}^{2}$ for dry season whereas 
D. K. Kidmo et al.

Table 5. Statistical indicators for the accuracy of satellite-derived wind speed at Kousseri and Maroua.

\begin{tabular}{|c|c|c|c|c|c|c|c|}
\hline & Seasons & $\begin{array}{c}C \\
(\mathrm{~m} / \mathrm{s})\end{array}$ & $\begin{array}{c}k \\
(-)\end{array}$ & $\begin{array}{c}V_{m} \\
(\mathrm{~m} / \mathrm{s})\end{array}$ & $\begin{array}{c}\rho \\
\left(\mathrm{kg} / \mathrm{m}^{3}\right)\end{array}$ & $\begin{array}{c}W_{P D} \\
\left(\mathrm{~W} / \mathrm{m}^{2}\right)\end{array}$ & $\begin{array}{c}E_{P D} \\
\left(\mathrm{kWh} / \mathrm{m}^{2} / \text { day }\right)\end{array}$ \\
\hline \multirow{2}{*}{ Bogo } & Dry & 4.38 & 3.39 & 3.93 & 1.12 & 44.98 & 1.08 \\
\hline & Rainy & 2.62 & 3.41 & 2.36 & 1.13 & 9.75 & 0.23 \\
\hline \multirow{2}{*}{ Gazawa } & Dry & 4.27 & 3.19 & 3.82 & 1.12 & 42.58 & 1.02 \\
\hline & Rainy & 2.49 & 3.22 & 2.23 & 1.13 & 8.51 & 0.20 \\
\hline \multirow{2}{*}{ Maroua } & Dry & 4.32 & 3.44 & 3.88 & 1.11 & 42.67 & 1.02 \\
\hline & Rainy & 2.63 & 3.39 & 2.37 & 1.12 & 9.80 & 0.24 \\
\hline \multirow{2}{*}{ Ndoukoula } & Dry & 4.42 & 3.16 & 3.96 & 1.11 & 47.23 & 1.13 \\
\hline & Rainy & 2.46 & 3.19 & 2.21 & 1.12 & 8.19 & 0.20 \\
\hline \multirow{2}{*}{ Blangoua } & Dry & 5.32 & 3.39 & 4.78 & 1.13 & 81.51 & 1.96 \\
\hline & Rainy & 3.47 & 3.17 & 3.11 & 1.13 & 23.09 & 0.55 \\
\hline \multirow{2}{*}{ Darak } & Dry & 4.51 & 3.47 & 4.05 & 1.12 & 48.81 & 1.17 \\
\hline & Rainy & 2.73 & 3.43 & 2.45 & 1.13 & 10.99 & 0.26 \\
\hline \multirow{2}{*}{ Fotokol } & Dry & 4.96 & 3.43 & 4.46 & 1.13 & 65.52 & 1.57 \\
\hline & Rainy & 3.12 & 3.19 & 2.79 & 1.13 & 16.79 & 0.40 \\
\hline \multirow{2}{*}{ Goulfey } & Dry & 5.01 & 3.42 & 4.50 & 1.13 & 67.56 & 1.62 \\
\hline & Rainy & 3.10 & 3.24 & 2.78 & 1.13 & 16.40 & 0.39 \\
\hline \multirow{2}{*}{ Hile-Alifa } & Dry & 5.42 & 3.41 & 4.87 & 1.13 & 85.77 & 2.06 \\
\hline & Rainy & 3.61 & 3.14 & 3.23 & 1.13 & 26.05 & 0.63 \\
\hline \multirow{2}{*}{ Kousséri } & Dry & 5.00 & 3.40 & 4.49 & 1.13 & 67.27 & 1.61 \\
\hline & Rainy & 3.04 & 3.23 & 2.73 & 1.13 & 15.51 & 0.37 \\
\hline \multirow{2}{*}{ Logone-Birni } & Dry & 4.83 & 3.42 & 4.34 & 1.13 & 60.50 & 1.45 \\
\hline & Rainy & 2.84 & 3.31 & 2.55 & 1.13 & 12.51 & 0.30 \\
\hline \multirow{2}{*}{ Gobo } & Dry & 3.83 & 3.10 & 3.43 & 1.12 & 31.10 & 0.75 \\
\hline & Rainy & 2.37 & 3.19 & 2.12 & 1.13 & 7.35 & 0.18 \\
\hline \multirow{2}{*}{ Kalfou } & Dry & 4.27 & 3.19 & 3.82 & 1.12 & 42.58 & 1.02 \\
\hline & Rainy & 2.49 & 3.22 & 2.23 & 1.13 & 8.51 & 0.20 \\
\hline \multirow{2}{*}{ Maga } & Dry & 4.38 & 3.39 & 3.93 & 1.12 & 44.98 & 1.08 \\
\hline & Rainy & 2.62 & 3.41 & 2.36 & 1.13 & 9.75 & 0.23 \\
\hline \multirow{2}{*}{ Yagoua } & Dry & 4.14 & 3.21 & 3.71 & 1.12 & 38.74 & 0.93 \\
\hline & Rainy & 2.47 & 3.23 & 2.21 & 1.13 & 8.32 & 0.20 \\
\hline \multirow{2}{*}{ Mora } & Dry & 4.29 & 3.54 & 3.86 & 1.12 & 41.71 & 1.00 \\
\hline & Rainy & 2.77 & 3.40 & 3.93 & 1.13 & 11.51 & 0.28 \\
\hline \multirow{2}{*}{ Bourrha } & Dry & 4.39 & 2.99 & 2.36 & 1.10 & 46.58 & 1.12 \\
\hline & Rainy & 2.44 & 3.07 & 3.82 & 1.11 & 8.00 & 0.19 \\
\hline \multirow{2}{*}{ Hina } & Dry & 4.43 & 3.11 & 2.23 & 1.10 & 47.13 & 1.13 \\
\hline & Rainy & 2.45 & 3.12 & 3.88 & 1.11 & 8.04 & 0.19 \\
\hline \multirow{2}{*}{ Mokolo } & Dry & 4.29 & 3.45 & 2.37 & 1.10 & 41.49 & 1.00 \\
\hline & Rainy & 2.68 & 3.30 & 3.96 & 1.11 & 10.30 & 0.25 \\
\hline \multirow{2}{*}{ Dziguilao } & Dry & 4.27 & 3.19 & 2.21 & 1.12 & 42.58 & 1.02 \\
\hline & Rainy & 2.49 & 3.22 & 4.78 & 1.13 & 8.51 & 0.20 \\
\hline \multirow{2}{*}{ Kaélé } & Dry & 4.42 & 3.16 & 3.11 & 1.11 & 47.23 & 1.13 \\
\hline & Rainy & 2.46 & 3.19 & 2.19 & 1.12 & 8.19 & 0.20 \\
\hline
\end{tabular}


Table 6. Seasonal variation of wind characteristics at $30 \mathrm{~m}$ height agl for the twenty-one locations.

\begin{tabular}{|c|c|c|c|c|c|c|c|c|c|}
\hline & Seasons & $\begin{array}{c}C \\
(\mathrm{~m} / \mathrm{s})\end{array}$ & $\begin{array}{c}k \\
(-)\end{array}$ & $\begin{array}{c}V_{m p} \\
(\mathrm{~m} / \mathrm{s})\end{array}$ & $\begin{array}{l}V_{\max E} \\
(\mathrm{~m} / \mathrm{s})\end{array}$ & $\begin{array}{c}V_{m} \\
(\mathrm{~m} / \mathrm{s})\end{array}$ & $\begin{array}{c}\rho \\
\left(\mathrm{kg} / \mathrm{m}^{3}\right)\end{array}$ & $\begin{array}{c}W_{P D} \\
\left(\mathrm{~W} / \mathrm{m}^{2}\right)\end{array}$ & $\begin{array}{c}E_{P D} \\
\left(\mathrm{kWh} / \mathrm{m}^{2} / \text { day }\right)\end{array}$ \\
\hline \multirow{2}{*}{ Bogo } & Dry & 5.04 & 2.85 & 4.33 & 6.08 & 4.49 & 1.12 & 73.64 & 5.04 \\
\hline & Rainy & 4.90 & 2.66 & 4.11 & 6.05 & 4.36 & 1.12 & 70.11 & 4.90 \\
\hline \multirow{2}{*}{ Gazawa } & Dry & 5.00 & 2.91 & 4.33 & 5.98 & 4.46 & 1.11 & 70.46 & 5.00 \\
\hline & Rainy & 5.02 & 2.57 & 4.14 & 6.27 & 4.45 & 1.11 & 76.14 & 5.02 \\
\hline \multirow{2}{*}{ Maroua } & Dry & 6.12 & 2.95 & 5.32 & 7.29 & 5.46 & 1.13 & 129.92 & 6.12 \\
\hline & Rainy & 5.19 & 2.93 & 4.50 & 6.20 & 4.63 & 1.12 & 79.36 & 5.19 \\
\hline \multirow{2}{*}{ Ndoukoula } & Dry & 5.70 & 2.93 & 4.94 & 6.80 & 5.08 & 1.13 & 105.21 & 5.70 \\
\hline & Rainy & 5.73 & 2.91 & 4.96 & 6.86 & 5.11 & 1.13 & 107.51 & 5.73 \\
\hline \multirow{2}{*}{ Blangoua } & Dry & 6.24 & 2.99 & 5.45 & 7.41 & 5.57 & 1.13 & 137.26 & 6.24 \\
\hline & Rainy & 5.70 & 2.87 & 4.91 & 6.86 & 5.08 & 1.13 & 106.54 & 5.70 \\
\hline \multirow{2}{*}{ Darak } & Dry & 5.49 & 2.84 & 4.71 & 6.63 & 4.89 & 1.13 & 95.67 & 5.49 \\
\hline & Rainy & 4.50 & 2.67 & 3.77 & 5.54 & 4.00 & 1.12 & 53.95 & 4.50 \\
\hline \multirow{2}{*}{ Fotokol } & Dry & 4.90 & 2.66 & 4.11 & 6.05 & 4.36 & 1.12 & 70.11 & 4.90 \\
\hline & Rainy & 5.04 & 2.85 & 4.33 & 6.08 & 4.49 & 1.12 & 73.64 & 5.04 \\
\hline \multirow{2}{*}{ Goulfey } & Dry & 4.79 & 2.71 & 4.04 & 5.88 & 4.26 & 1.12 & 64.83 & 4.79 \\
\hline & Rainy & 5.03 & 3.07 & 4.42 & 5.92 & 4.49 & 1.12 & 70.40 & 5.03 \\
\hline \multirow{2}{*}{ Hile-Alifa } & Dry & 4.97 & 2.45 & 4.02 & 6.34 & 4.41 & 1.10 & 75.70 & 4.97 \\
\hline & Rainy & 5.01 & 2.53 & 4.11 & 6.31 & 4.45 & 1.10 & 75.99 & 5.01 \\
\hline \multirow{2}{*}{ Kousséri } & Dry & 5.00 & 2.94 & 4.34 & 5.96 & 4.46 & 1.10 & 69.22 & 5.00 \\
\hline & Rainy & 4.90 & 2.66 & 4.11 & 6.05 & 4.36 & 1.12 & 70.11 & 4.90 \\
\hline \multirow{2}{*}{ Logone-Birni } & Dry & 5.02 & 2.57 & 4.14 & 6.27 & 4.45 & 1.11 & 76.14 & 5.02 \\
\hline & Rainy & 5.04 & 2.85 & 4.33 & 6.08 & 4.49 & 1.12 & 73.64 & 5.04 \\
\hline \multirow{2}{*}{ Gobo } & Dry & 4.90 & 2.66 & 4.11 & 6.05 & 4.36 & 1.12 & 70.11 & 4.90 \\
\hline & Rainy & 5.00 & 2.91 & 4.33 & 5.98 & 4.46 & 1.11 & 70.46 & 5.00 \\
\hline \multirow{2}{*}{ Kalfou } & Dry & 5.02 & 2.57 & 4.14 & 6.27 & 4.45 & 1.11 & 76.14 & 5.02 \\
\hline & Rainy & 6.12 & 2.95 & 5.32 & 7.29 & 5.46 & 1.13 & 129.92 & 6.12 \\
\hline \multirow{2}{*}{ Maga } & Dry & 5.19 & 2.93 & 4.50 & 6.20 & 4.63 & 1.12 & 79.36 & 5.19 \\
\hline & Rainy & 5.70 & 2.93 & 4.94 & 6.80 & 5.08 & 1.13 & 105.21 & 5.70 \\
\hline \multirow{2}{*}{ Yagoua } & Dry & 5.73 & 2.91 & 4.96 & 6.86 & 5.11 & 1.13 & 107.51 & 5.73 \\
\hline & Rainy & 6.24 & 2.99 & 5.45 & 7.41 & 5.57 & 1.13 & 137.26 & 6.24 \\
\hline \multirow{2}{*}{ Mora } & Dry & 5.70 & 2.87 & 4.91 & 6.86 & 5.08 & 1.13 & 106.54 & 5.70 \\
\hline & Rainy & 5.49 & 2.84 & 4.71 & 6.63 & 4.89 & 1.13 & 95.67 & 5.49 \\
\hline \multirow{2}{*}{ Bourrha } & Dry & 4.50 & 2.67 & 3.77 & 5.54 & 4.00 & 1.12 & 53.95 & 4.50 \\
\hline & Rainy & 4.90 & 2.66 & 4.11 & 6.05 & 4.36 & 1.12 & 70.11 & 4.90 \\
\hline \multirow{2}{*}{ Hina } & Dry & 5.04 & 2.85 & 4.33 & 6.08 & 4.49 & 1.12 & 73.64 & 5.04 \\
\hline & Rainy & 4.79 & 2.71 & 4.04 & 5.88 & 4.26 & 1.12 & 64.83 & 4.79 \\
\hline \multirow{2}{*}{ Mokolo } & Dry & 5.03 & 3.07 & 4.42 & 5.92 & 4.49 & 1.12 & 70.40 & 5.03 \\
\hline & Rainy & 4.97 & 2.45 & 4.02 & 6.34 & 4.41 & 1.10 & 75.70 & 4.97 \\
\hline \multirow{2}{*}{ Dziguilao } & Dry & 5.01 & 2.53 & 4.11 & 6.31 & 4.45 & 1.10 & 75.99 & 5.01 \\
\hline & Rainy & 5.00 & 2.94 & 4.34 & 5.96 & 4.46 & 1.10 & 69.22 & 5.00 \\
\hline \multirow{2}{*}{ Kaélé } & Dry & 4.90 & 2.66 & 4.11 & 6.05 & 4.36 & 1.12 & 70.11 & 4.90 \\
\hline & Rainy & 5.02 & 2.57 & 4.14 & 6.27 & 4.45 & 1.11 & 76.14 & 5.02 \\
\hline
\end{tabular}


the corresponding values for rainy season range from 19.26 to $60.44 \mathrm{~W} / \mathrm{m}^{2}$. Mean energy density values fluctuate from 1.70 to $4.25 \mathrm{kWh} / \mathrm{m}^{2} /$ day and from 0.46 to $1.45 \mathrm{kWh} / \mathrm{m}^{2} /$ day, respectively for dry and rainy seasons.

Table 7 presents mean seasonal frequency for the six selected wind turbines to produce power at the twenty-one locations. mean seasonal frequency values represent the availability of wind during which WT produce power. Based on WT characteristics, it is observed a trend of probability to produce power that is highest using $\mathrm{WT}_{1}$ and $\mathrm{WT}_{2}(0.99-0.82)$, followed by $\mathrm{WT}_{3}(0.97-0.66) . \mathrm{WT}_{4}$, $\mathrm{WT}_{5}$ and $\mathrm{WT}_{6}$ show the lowest seasonal probability $(0.95-0.47)$ to produce power. As a result, WT with lower cut-in $\mathrm{WS}\left(\mathrm{WT}_{1}\right.$ and $\mathrm{WT}_{2}$ ) display a higher probability to produce power, in comparison to WT presenting higher cut-in $\mathrm{WS}\left(\mathrm{WT}_{4}, \mathrm{WT}_{5}\right.$ and $\left.\mathrm{WT}_{6}\right)$.

\subsection{Cost of Energy}

Table 8 and Table 9 illustrate, respectively mean seasonal capacity factor (CF) and costs of energy (COE), for the six selected WT at the twenty-one selected locations. Mean seasonal CF values show the ranking of selected WT. $\mathrm{WT}_{1}$ achieves the first position, whereas $\mathrm{WT}_{3}$ and $\mathrm{WT}_{2}$ take, respectively the second and third positions in rank. Although $\mathrm{WT}_{4}$ gets the fourth position, it displays the same performance as $\mathrm{WT}_{5}$. The least efficient is $\mathrm{WT}_{6}$. It is observed that the $\mathrm{CF}$ is characteristically affected by the WT cut-in and rated WS while the cut-out WS has insignificant impact on the CF. The first four locations that show the highest mean seasonal CF values are Hile-Alifa, Blangoua, Kousseri and Goulfey, in that order. With respects to $\mathrm{WT}_{1}$, the most efficient of considered WT, mean seasonal CF values for dry and rainy seasons display, respectively $26.93 \%$ and $9.13 \%$ at Hile-Alifa, $25.79 \%$ and $7.94 \%$ at Blangoua, $21.32 \%$ and $4.99 \%$ at Kousseri, and $21.27 \%$ and $5.28 \%$ at Goulfey. Similarly, mean seasonal COE provide also the ranking of selected WT, based on cost per kWh of energy produced. CF and $\mathrm{COE}$ values followed the same trend when ranking WT performance. The lowest costs per kWh are obtained using $\mathrm{WT}_{1}$, while the $2^{\text {nd }}$ and $3^{\text {rd }}$ third positions in rank are taken, respectively by $\mathrm{WT}_{3}$ and $\mathrm{WT}_{2}$. $\mathrm{WT}_{4}$ and $\mathrm{WT}_{5}$ exhibit the same performance. $\mathrm{WT}_{6}$ shows the highest cost per $\mathrm{kWh}$ of energy produced. With respects to $\mathrm{WT}_{1}$, the most cost-effective of considered WT, dry season COE values are 68.84, 71.97, 87.30 and 87.47 XAF/kWh at Hile-Alifa, Blangoua, Kousseri and Goulfey, in that order. Rainy season Corresponding COE values stand at 213.18, 246.60, 402.95 and 379.07 XAF/kWh.

Figure 10 illustrates mean monthly CF and COE plotting using WT1, at (a) Blangoua, (b) Goulfey, (c) Hilé-Alifa and (d) Kousseri. With respect to the PVC method, COE are inversely proportional to CF. It is seen that the higher the CF, the lower the COE. Lower COE are observed in dry season, whereas higher COE are experienced in rainy season. The highest COE are revealed in September followed by August, while the lowest COE are shown in March followed by February. 
Table 7. Average seasonal frequency for selected wind turbines to produce power at the twenty-one locations.

\begin{tabular}{|c|c|c|c|c|c|c|c|}
\hline Locations & Seasons & WT1 & WT2 & WT3 & WT4 & WT5 & WT6 \\
\hline \multirow{2}{*}{ Bogo } & Dry & $97.25 \%$ & $97.25 \%$ & $94.20 \%$ & $89.45 \%$ & $89.45 \%$ & $89.45 \%$ \\
\hline & Rainy & $87.46 \%$ & $87.46 \%$ & $74.93 \%$ & $58.26 \%$ & $58.26 \%$ & $58.26 \%$ \\
\hline \multirow{2}{*}{ Gazawa } & Dry & $96.39 \%$ & $96.39 \%$ & $92.73 \%$ & $87.30 \%$ & $87.30 \%$ & $87.30 \%$ \\
\hline & Rainy & $84.08 \%$ & $84.08 \%$ & $69.86 \%$ & $52.23 \%$ & $52.23 \%$ & $52.23 \%$ \\
\hline \multirow{2}{*}{ Maroua } & Dry & $97.30 \%$ & $97.30 \%$ & $94.22 \%$ & $89.38 \%$ & $89.38 \%$ & $89.38 \%$ \\
\hline & Rainy & $87.53 \%$ & $87.53 \%$ & $75.11 \%$ & $58.59 \%$ & $58.59 \%$ & $58.59 \%$ \\
\hline \multirow{2}{*}{ Ndoukoula } & Dry & $96.61 \%$ & $96.61 \%$ & $93.22 \%$ & $88.20 \%$ & $88.20 \%$ & $88.20 \%$ \\
\hline & Rainy & $83.31 \%$ & $83.31 \%$ & $68.74 \%$ & $50.93 \%$ & $50.93 \%$ & $50.93 \%$ \\
\hline \multirow{2}{*}{ Blangoua } & Dry & $98.50 \%$ & $98.50 \%$ & $96.80 \%$ & $94.11 \%$ & $94.11 \%$ & $94.11 \%$ \\
\hline & Rainy & $93.35 \%$ & $93.35 \%$ & $86.89 \%$ & $77.75 \%$ & $77.75 \%$ & $77.75 \%$ \\
\hline \multirow{2}{*}{ Darak } & Dry & $97.71 \%$ & $97.71 \%$ & $95.06 \%$ & $90.84 \%$ & $90.84 \%$ & $90.84 \%$ \\
\hline & Rainy & $88.99 \%$ & $88.99 \%$ & $77.68 \%$ & $62.22 \%$ & $62.22 \%$ & $62.22 \%$ \\
\hline \multirow{2}{*}{ Fotokol } & Dry & $98.22 \%$ & $98.22 \%$ & $96.18 \%$ & $92.94 \%$ & $92.94 \%$ & $92.94 \%$ \\
\hline & Rainy & $91.19 \%$ & $91.19 \%$ & $82.77 \%$ & $71.19 \%$ & $71.19 \%$ & $71.19 \%$ \\
\hline \multirow{2}{*}{ Goulfey } & Dry & $98.25 \%$ & $98.25 \%$ & $96.26 \%$ & $93.09 \%$ & $93.09 \%$ & $93.09 \%$ \\
\hline & Rainy & $91.38 \%$ & $91.38 \%$ & $82.94 \%$ & $71.21 \%$ & $71.21 \%$ & $71.21 \%$ \\
\hline \multirow{2}{*}{ Hile-Alifa } & Dry & $98.61 \%$ & $98.61 \%$ & $97.02 \%$ & $94.50 \%$ & $94.50 \%$ & $94.50 \%$ \\
\hline & Rainy & $93.89 \%$ & $93.89 \%$ & $88.01 \%$ & $79.63 \%$ & $79.63 \%$ & $79.63 \%$ \\
\hline \multirow{2}{*}{ Kousséri } & Dry & $98.20 \%$ & $98.20 \%$ & $96.16 \%$ & $92.94 \%$ & $92.94 \%$ & $92.94 \%$ \\
\hline & Rainy & $90.86 \%$ & $90.86 \%$ & $81.99 \%$ & $69.77 \%$ & $69.77 \%$ & $69.77 \%$ \\
\hline \multirow{2}{*}{ Logone-Birni } & Dry & $98.04 \%$ & $98.04 \%$ & $95.81 \%$ & $92.28 \%$ & $92.28 \%$ & $92.28 \%$ \\
\hline & Rainy & $89.44 \%$ & $89.44 \%$ & $79.04 \%$ & $64.88 \%$ & $64.88 \%$ & $64.88 \%$ \\
\hline \multirow{2}{*}{ Gobo } & Dry & $94.65 \%$ & $94.65 \%$ & $89.53 \%$ & $82.23 \%$ & $82.23 \%$ & $82.23 \%$ \\
\hline & Rainy & $81.51 \%$ & $81.51 \%$ & $65.73 \%$ & $46.99 \%$ & $46.99 \%$ & $46.99 \%$ \\
\hline \multirow{2}{*}{ Kalfou } & Dry & $96.39 \%$ & $96.39 \%$ & $92.73 \%$ & $87.30 \%$ & $87.30 \%$ & $87.30 \%$ \\
\hline & Rainy & $84.08 \%$ & $84.08 \%$ & $69.86 \%$ & $52.23 \%$ & $52.23 \%$ & $52.23 \%$ \\
\hline \multirow{2}{*}{ Maga } & Dry & $97.25 \%$ & $97.25 \%$ & $94.20 \%$ & $89.45 \%$ & $89.45 \%$ & $89.45 \%$ \\
\hline & Rainy & $87.46 \%$ & $87.46 \%$ & $74.93 \%$ & $58.26 \%$ & $58.26 \%$ & $58.26 \%$ \\
\hline \multirow{2}{*}{ Yagoua } & Dry & $96.11 \%$ & $96.11 \%$ & $92.15 \%$ & $86.28 \%$ & $86.28 \%$ & $86.28 \%$ \\
\hline & Rainy & $83.81 \%$ & $83.81 \%$ & $69.34 \%$ & $51.46 \%$ & $51.46 \%$ & $51.46 \%$ \\
\hline \multirow{2}{*}{ Mora } & Dry & $97.51 \%$ & $97.51 \%$ & $94.55 \%$ & $89.80 \%$ & $89.80 \%$ & $89.80 \%$ \\
\hline & Rainy & $89.32 \%$ & $89.32 \%$ & $78.42 \%$ & $63.48 \%$ & $63.48 \%$ & $63.48 \%$ \\
\hline \multirow{2}{*}{ Bourrha } & Dry & $95.87 \%$ & $95.87 \%$ & $92.06 \%$ & $86.64 \%$ & $86.64 \%$ & $86.64 \%$ \\
\hline & Rainy & $81.82 \%$ & $81.82 \%$ & $67.00 \%$ & $49.44 \%$ & $49.44 \%$ & $49.44 \%$ \\
\hline \multirow{2}{*}{ Hina } & Dry & $96.45 \%$ & $96.45 \%$ & $92.98 \%$ & $87.90 \%$ & $87.90 \%$ & $87.90 \%$ \\
\hline & Rainy & $82.44 \%$ & $82.44 \%$ & $67.72 \%$ & $50.05 \%$ & $50.05 \%$ & $50.05 \%$ \\
\hline \multirow{2}{*}{ Mokolo } & Dry & $97.28 \%$ & $97.28 \%$ & $94.17 \%$ & $89.28 \%$ & $89.28 \%$ & $89.28 \%$ \\
\hline & Rainy & $87.46 \%$ & $87.46 \%$ & $75.45 \%$ & $59.64 \%$ & $59.64 \%$ & $59.64 \%$ \\
\hline \multirow{2}{*}{ Dziguilao } & Dry & $96.39 \%$ & $96.39 \%$ & $92.73 \%$ & $87.30 \%$ & $87.30 \%$ & $87.30 \%$ \\
\hline & Rainy & $84.08 \%$ & $84.08 \%$ & $69.86 \%$ & $52.23 \%$ & $52.23 \%$ & $52.23 \%$ \\
\hline \multirow{2}{*}{ Kaélé } & Dry & $96.61 \%$ & $96.61 \%$ & $93.22 \%$ & $88.20 \%$ & $88.20 \%$ & $88.20 \%$ \\
\hline & Rainy & $83.31 \%$ & $83.31 \%$ & $68.74 \%$ & $50.93 \%$ & $50.93 \%$ & $50.93 \%$ \\
\hline
\end{tabular}


D. K. Kidmo et al.

Table 8. Average seasonal capacities factors for selected wind turbines at the twenty-one locations.

\begin{tabular}{|c|c|c|c|c|c|c|c|}
\hline Locations & Seasons & WT1 & WT2 & WT3 & WT4 & WT5 & WT6 \\
\hline \multirow{2}{*}{ Bogo } & Dry & $14.26 \%$ & $10.29 \%$ & $13.87 \%$ & $9.55 \%$ & $9.55 \%$ & $7.07 \%$ \\
\hline & Rainy & $2.59 \%$ & $1.86 \%$ & $2.23 \%$ & $1.25 \%$ & $1.25 \%$ & $0.93 \%$ \\
\hline \multirow{2}{*}{ Gazawa } & Dry & $14.69 \%$ & $10.80 \%$ & $14.22 \%$ & $9.89 \%$ & $9.89 \%$ & $7.45 \%$ \\
\hline & Rainy & $2.58 \%$ & $1.89 \%$ & $2.16 \%$ & $1.19 \%$ & $1.19 \%$ & $0.89 \%$ \\
\hline \multirow{2}{*}{ Maroua } & Dry & $13.23 \%$ & $9.49 \%$ & $12.87 \%$ & $8.79 \%$ & $8.79 \%$ & $6.48 \%$ \\
\hline & Rainy & $2.65 \%$ & $1.91 \%$ & $2.29 \%$ & $1.29 \%$ & $1.29 \%$ & $0.96 \%$ \\
\hline \multirow{2}{*}{ Ndoukoula } & Dry & $16.62 \%$ & $12.28 \%$ & $16.14 \%$ & $11.34 \%$ & $11.34 \%$ & $8.57 \%$ \\
\hline & Rainy & $2.56 \%$ & $1.88 \%$ & $2.12 \%$ & $1.16 \%$ & $1.16 \%$ & $0.87 \%$ \\
\hline \multirow{2}{*}{ Blangoua } & Dry & $25.79 \%$ & $18.94 \%$ & $25.45 \%$ & $18.25 \%$ & $18.25 \%$ & $13.58 \%$ \\
\hline & Rainy & $7.94 \%$ & $5.85 \%$ & $7.44 \%$ & $4.93 \%$ & $4.93 \%$ & $3.72 \%$ \\
\hline \multirow{2}{*}{ Darak } & Dry & $14.92 \%$ & $10.68 \%$ & $14.57 \%$ & $10.01 \%$ & $10.01 \%$ & $7.36 \%$ \\
\hline & Rainy & $2.92 \%$ & $2.10 \%$ & $2.56 \%$ & $1.48 \%$ & $1.48 \%$ & $1.09 \%$ \\
\hline \multirow{2}{*}{ Fotokol } & Dry & $20.54 \%$ & $14.86 \%$ & $20.20 \%$ & $14.18 \%$ & $14.18 \%$ & $10.47 \%$ \\
\hline & Rainy & $5.61 \%$ & $4.13 \%$ & $5.13 \%$ & $3.26 \%$ & $3.26 \%$ & $2.45 \%$ \\
\hline \multirow{2}{*}{ Goulfey } & Dry & $21.27 \%$ & $15.42 \%$ & $20.93 \%$ & $14.73 \%$ & $14.73 \%$ & $10.89 \%$ \\
\hline & Rainy & $5.28 \%$ & $3.86 \%$ & $4.82 \%$ & $3.04 \%$ & $3.04 \%$ & $2.28 \%$ \\
\hline \multirow{2}{*}{ Hile-Alifa } & Dry & $26.93 \%$ & $19.80 \%$ & $26.61 \%$ & $19.14 \%$ & $19.14 \%$ & $14.23 \%$ \\
\hline & Rainy & $9.13 \%$ & $6.74 \%$ & $8.61 \%$ & $5.79 \%$ & $5.79 \%$ & $4.37 \%$ \\
\hline \multirow{2}{*}{ Kousséri } & Dry & $21.32 \%$ & $15.49 \%$ & $20.97 \%$ & $14.79 \%$ & $14.79 \%$ & $10.95 \%$ \\
\hline & Rainy & $4.99 \%$ & $3.65 \%$ & $4.53 \%$ & $2.84 \%$ & $2.84 \%$ & $2.13 \%$ \\
\hline \multirow{2}{*}{ Logone-Birni } & Dry & $19.06 \%$ & $13.78 \%$ & $18.71 \%$ & $13.08 \%$ & $13.08 \%$ & $9.66 \%$ \\
\hline & Rainy & $3.71 \%$ & $2.70 \%$ & $3.30 \%$ & $1.98 \%$ & $1.98 \%$ & $1.47 \%$ \\
\hline \multirow{2}{*}{ Gobo } & Dry & $11.25 \%$ & $8.34 \%$ & $10.71 \%$ & $7.33 \%$ & $7.33 \%$ & $5.56 \%$ \\
\hline & Rainy & $2.24 \%$ & $1.64 \%$ & $1.82 \%$ & $0.96 \%$ & $0.96 \%$ & $0.72 \%$ \\
\hline \multirow{2}{*}{ Kalfou } & Dry & $14.69 \%$ & $10.80 \%$ & $14.22 \%$ & $9.89 \%$ & $9.89 \%$ & $7.45 \%$ \\
\hline & Rainy & $2.58 \%$ & $1.89 \%$ & $2.16 \%$ & $1.19 \%$ & $1.19 \%$ & $0.89 \%$ \\
\hline \multirow{2}{*}{ Maga } & Dry & $14.26 \%$ & $10.29 \%$ & $13.87 \%$ & $9.55 \%$ & $9.55 \%$ & $7.07 \%$ \\
\hline & Rainy & $2.59 \%$ & $1.86 \%$ & $2.23 \%$ & $1.25 \%$ & $1.25 \%$ & $0.93 \%$ \\
\hline \multirow{2}{*}{ Yagoua } & Dry & $13.25 \%$ & $9.73 \%$ & $12.78 \%$ & $8.83 \%$ & $8.83 \%$ & $6.63 \%$ \\
\hline & Rainy & $2.48 \%$ & $1.82 \%$ & $2.07 \%$ & $1.13 \%$ & $1.13 \%$ & $0.85 \%$ \\
\hline \multirow{2}{*}{ Mora } & Dry & $12.22 \%$ & $8.68 \%$ & $11.89 \%$ & $8.05 \%$ & $8.05 \%$ & $5.88 \%$ \\
\hline & Rainy & $3.16 \%$ & $2.28 \%$ & $2.79 \%$ & $1.63 \%$ & $1.63 \%$ & $1.21 \%$ \\
\hline \multirow{2}{*}{ Bourrha } & Dry & $17.69 \%$ & $13.29 \%$ & $17.11 \%$ & $12.18 \%$ & $12.18 \%$ & $9.33 \%$ \\
\hline & Rainy & $2.81 \%$ & $2.09 \%$ & $2.31 \%$ & $1.28 \%$ & $1.28 \%$ & $0.97 \%$ \\
\hline \multirow{2}{*}{ Hina } & Dry & $17.07 \%$ & $12.67 \%$ & $16.56 \%$ & $11.69 \%$ & $11.69 \%$ & $8.86 \%$ \\
\hline & Rainy & $2.71 \%$ & $2.00 \%$ & $2.24 \%$ & $1.23 \%$ & $1.23 \%$ & $0.93 \%$ \\
\hline \multirow{2}{*}{ Mokolo } & Dry & $12.92 \%$ & $9.26 \%$ & $12.56 \%$ & $8.57 \%$ & $8.57 \%$ & $6.31 \%$ \\
\hline & Rainy & $3.09 \%$ & $2.25 \%$ & $2.68 \%$ & $1.55 \%$ & $1.55 \%$ & $1.16 \%$ \\
\hline \multirow{2}{*}{ Dziguilao } & Dry & $14.69 \%$ & $10.80 \%$ & $14.22 \%$ & $9.89 \%$ & $9.89 \%$ & $7.45 \%$ \\
\hline & Rainy & $2.58 \%$ & $1.89 \%$ & $2.16 \%$ & $1.19 \%$ & $1.19 \%$ & $0.89 \%$ \\
\hline \multirow{2}{*}{ Kaélé } & Dry & $16.62 \%$ & $12.28 \%$ & $16.14 \%$ & $11.34 \%$ & $11.34 \%$ & $8.57 \%$ \\
\hline & Rainy & $2.56 \%$ & $1.88 \%$ & $2.12 \%$ & $1.16 \%$ & $1.16 \%$ & $0.87 \%$ \\
\hline
\end{tabular}


Table 9. Average seasonal costs of energy for selected wind turbines at the twenty-one locations.

\begin{tabular}{|c|c|c|c|c|c|c|c|}
\hline Locations & Seasons & WT1 & WT2 & WT3 & WT4 & WT5 & WT6 \\
\hline \multirow{2}{*}{ Bogo } & Dry & 131.86 & 182.68 & 139.90 & 214.04 & 214.04 & 289.06 \\
\hline & Rainy & 807.79 & 1122.32 & 1095.47 & 2507.25 & 2507.25 & 3391.92 \\
\hline \multirow{2}{*}{ Gazawa } & Dry & 129.07 & 175.54 & 138.64 & 211.63 & 211.63 & 281.18 \\
\hline & Rainy & 842.37 & 1150.54 & 1213.16 & 2949.00 & 2949.00 & 3929.18 \\
\hline \multirow{2}{*}{ Maroua } & Dry & 142.05 & 197.93 & 150.82 & 232.60 & 232.60 & 315.65 \\
\hline & Rainy & 787.29 & 1092.69 & 1064.11 & 2417.18 & 2417.18 & 3267.00 \\
\hline \multirow{2}{*}{ Ndoukoula } & Dry & 113.83 & 154.08 & 121.52 & 182.72 & 182.72 & 241.98 \\
\hline & Rainy & 857.58 & 1167.84 & 1252.35 & 3090.89 & 3090.89 & 4107.35 \\
\hline \multirow{2}{*}{ Blangoua } & Dry & 71.97 & 98.00 & 74.20 & 106.44 & 106.44 & 143.09 \\
\hline & Rainy & 246.60 & 334.97 & 282.86 & 477.32 & 477.32 & 632.87 \\
\hline \multirow{2}{*}{ Darak } & Dry & 125.42 & 175.16 & 131.96 & 201.05 & 201.05 & 273.55 \\
\hline & Rainy & 703.12 & 978.82 & 918.51 & 1985.43 & 1985.43 & 2690.71 \\
\hline \multirow{2}{*}{ Fotokol } & Dry & 90.60 & 125.28 & 94.08 & 138.76 & 138.76 & 187.92 \\
\hline & Rainy & 357.05 & 485.86 & 430.75 & 788.29 & 788.29 & 1046.82 \\
\hline \multirow{2}{*}{ Goulfey } & Dry & 87.47 & 120.66 & 90.74 & 133.28 & 133.28 & 180.27 \\
\hline & Rainy & 379.07 & 518.41 & 457.55 & 844.65 & 844.65 & 1126.67 \\
\hline \multirow{2}{*}{ Hile-Alifa } & Dry & 68.84 & 93.61 & 70.81 & 101.09 & 101.09 & 135.96 \\
\hline & Rainy & 213.18 & 288.82 & 241.15 & 396.77 & 396.77 & 524.86 \\
\hline \multirow{2}{*}{ Kousséri } & Dry & 87.30 & 120.19 & 90.64 & 133.02 & 133.02 & 179.58 \\
\hline & Rainy & 402.95 & 550.68 & 492.04 & 924.01 & 924.01 & 1231.77 \\
\hline \multirow{2}{*}{ Logone-Birni } & Dry & 97.82 & 135.37 & 101.97 & 151.50 & 151.50 & 205.03 \\
\hline & Rainy & 550.33 & 757.74 & 701.10 & 1426.09 & 1426.09 & 1913.77 \\
\hline \multirow{2}{*}{ Gobo } & Dry & 171.68 & 231.68 & 190.59 & 303.12 & 303.12 & 399.63 \\
\hline & Rainy & 1001.43 & 1363.60 & 1531.03 & 4057.78 & 4057.78 & 5391.72 \\
\hline \multirow{2}{*}{ Kalfou } & Dry & 129.07 & 175.54 & 138.64 & 211.63 & 211.63 & 281.18 \\
\hline & Rainy & 842.37 & 1150.54 & 1213.16 & 2949.00 & 2949.00 & 3929.18 \\
\hline \multirow{2}{*}{ Maga } & Dry & 131.86 & 182.68 & 139.90 & 214.04 & 214.04 & 289.06 \\
\hline & Rainy & 807.79 & 1122.32 & 1095.47 & 2507.25 & 2507.25 & 3391.92 \\
\hline \multirow{2}{*}{ Yagoua } & Dry & 143.52 & 195.59 & 155.22 & 240.03 & 240.03 & 319.33 \\
\hline & Rainy & 878.20 & 1200.64 & 1275.79 & 3150.44 & 3150.44 & 4201.18 \\
\hline \multirow{2}{*}{ Mora } & Dry & 153.46 & 215.98 & 162.59 & 252.80 & 252.80 & 346.06 \\
\hline & Rainy & 646.93 & 898.34 & 835.25 & 1762.94 & 1762.94 & 2383.80 \\
\hline \multirow{2}{*}{ Bourrha } & Dry & 107.79 & 143.47 & 116.03 & 173.21 & 173.21 & 226.15 \\
\hline & Rainy & 796.12 & 1071.45 & 1179.20 & 2897.45 & 2897.45 & 3810.16 \\
\hline \multirow{2}{*}{ Hina } & Dry & 111.01 & 149.54 & 118.69 & 177.89 & 177.89 & 234.65 \\
\hline & Rainy & 819.23 & 1107.74 & 1206.38 & 2968.92 & 2968.92 & 3920.48 \\
\hline \multirow{2}{*}{ Mokolo } & Dry & 145.41 & 202.84 & 154.50 & 238.87 & 238.87 & 324.45 \\
\hline & Rainy & 676.21 & 929.86 & 903.77 & 1979.63 & 1979.63 & 2653.54 \\
\hline \multirow{2}{*}{ Dziguilao } & Dry & 129.07 & 175.54 & 138.64 & 211.63 & 211.63 & 281.18 \\
\hline & Rainy & 842.37 & 1150.54 & 1213.16 & 2949.00 & 2949.00 & 3929.18 \\
\hline \multirow{2}{*}{ Kaélé } & Dry & 113.83 & 154.08 & 121.52 & 182.72 & 182.72 & 241.98 \\
\hline & Rainy & 857.58 & 1167.84 & 1252.35 & 3090.89 & 3090.89 & 4107.35 \\
\hline
\end{tabular}




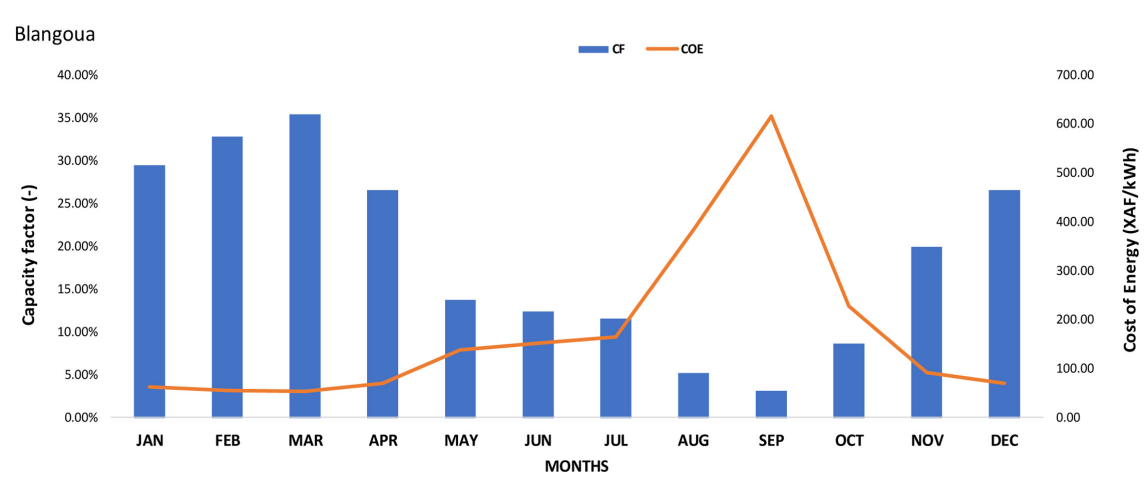

(a)

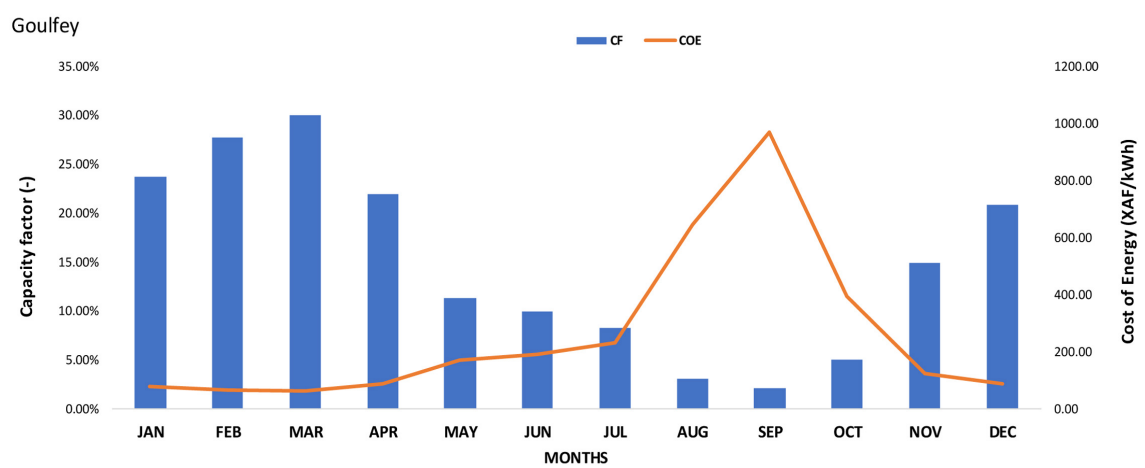

(b)

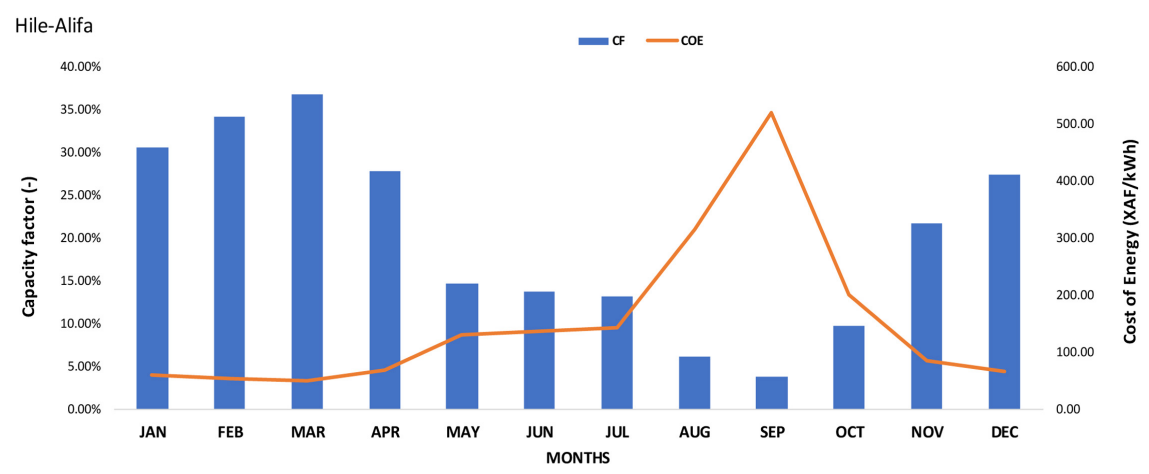

(c)

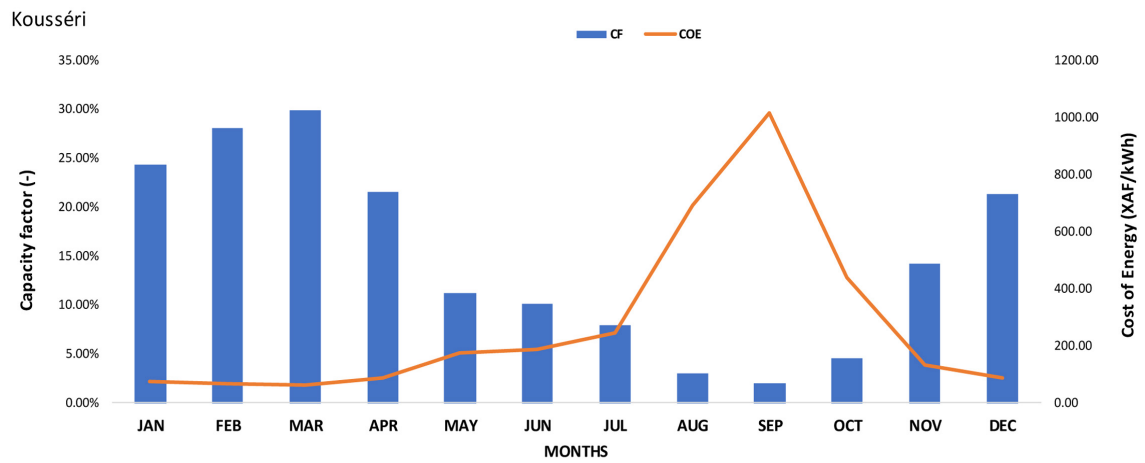

(d)

Figure 10. Mean monthly CF and COE using WT1, at (a) Blangoua, (b) Goulfey, (c) Hilé-Alifa and (d) Kousseri. 


\subsection{Flow Rate Capacity}

Table 10 discloses mean seasonal flow rate capacity $\left(\mathrm{m}^{4} / \mathrm{h}\right)$ using the six selected $\mathrm{WT}$ at the twenty-one considered locations. $\mathrm{WT}_{1}$ achieves the highest flow rate capacity, whereas $\mathrm{WT}_{3}, \mathrm{WT}_{2}$ and $\mathrm{WT}_{4}$ rank, respectively $2^{\text {nd }}, 3^{\text {rd }}$ and $4^{\text {th }} . \mathrm{WT}_{4}$ reveals the same performance as $\mathrm{WT}_{5}$. The least efficient is $\mathrm{WT}_{6}$. Flow rate capacity and CF are linearly related to each other; hence they follow the same trend when ranking $\mathrm{WT}$ performance. With consideration to $\mathrm{WT}_{1}$, the most performing of considered WT, dry season flow rate capacity values are $612.69,585.99$, 483.08 and $482.19 \mathrm{~m}^{4} / \mathrm{h}$ at Hile-Alifa, Blangoua, Kousseri and Goulfey, in that order. Rainy season Corresponding values stand at 197.83, 171.03, 104.67 and $111.26 \mathrm{~m}^{4} / \mathrm{h}$. The upper range possible for mechanical wind pumps is about 2500 $\mathrm{m}^{4} /$ day and for larger power requirements, above $2500 \mathrm{~m}^{4} /$ day, the electrical wind pumping is the most cost-effective option [43]. Wind electric pumping system can be implemented at Hilé-Alifa, Blangoua, Kousseri and Goulfey, using WT characteristics similar to $\mathrm{WT}_{1}$. Based on hydraulic requirements for wind pumps, the use of Mechanical wind pumping system is highly suggested as the most cost-effective option of wind pumping technologies in FNR.

Figure 11 shows mean monthly flow rate capacity $\left(\mathrm{m}^{4} / \mathrm{h}\right)$ histograms using $\mathrm{WT}_{1}$, at (a) Blangoua, (b) Goulfey, (c) Hilé-Alifa and (d) Kousseri. Higher flow rate capacity are observed in dry season, whereas lower values are seen in rainy season. The lowest flow rate capacity are observed in September followed by August, whereas the highest values are shown in March followed by February.

\subsection{Volumetric Flow Rate of Water ( $\mathrm{m}^{3} /$ day) at $50 \mathrm{~m}$ Dynamic Head}

Table 11 illustrates mean seasonal volumetric flow rate of water $\left(\mathrm{m}^{3} /\right.$ day $)$ at 50 $\mathrm{m}$ dynamic head using the six selected WT at the twenty-one selected locations. Volumetric flow rate $\left(Q_{w}\right)$ and flow rate capacity $\left(F_{w}\right)$ are lineary related to each other, hence they follow the same trend when ranking WT performance. $\mathrm{WT}_{1}$ achieves the highest volumetric flow rate, whereas $\mathrm{WT}_{3}, \mathrm{WT}_{2}$ and $\mathrm{WT}_{4}$ rank, respectively $2^{\text {nd }}, 3^{\text {rd }}$ and $4^{\text {th }} . \mathrm{WT}_{4}$ reveals the same performance as $\mathrm{WT}_{5}$. The least efficient is $\mathrm{WT}_{6}$. With consideration to $\mathrm{WT}_{1}$, the most performing of considered WT, dry season volumetric flow rate of water are 490.96, 449.11, 305.22 and $304.10 \mathrm{~m}^{3} /$ day at Hile-Alifa, Blangoua, Kousseri and Goulfey, in that order. Rainy season corresponding values stand at $51.19,38.26,14.33$ and $16.19 \mathrm{~m}^{3} /$ day.

\subsection{Cost of Water}

Table 12 illustrates mean seasonal costs of water $\left(\mathrm{XAF} / \mathrm{m}^{3}\right)$ at $50 \mathrm{~m}$ dynamic head using the six selected WT at the twenty-one selected locations. COW and flow rate capacity are lineary related to each other, hence they follow the same tendency when ranking $\mathrm{WT}$ performance. $\mathrm{WT}_{1}$ achieves the highest volumetric flow rate, whereas $\mathrm{WT}_{3}, \mathrm{WT}_{2}$ and $\mathrm{WT}_{4}$ rank, respectively $2^{\text {nd }}, 3^{\text {rd }}$ and $4^{\text {th }} . \mathrm{WT}_{4}$ reveals the same performance as $\mathrm{WT}_{5}$. The least efficient is $\mathrm{WT}_{6}$. With consideration to $\mathrm{WT}_{1}$, the most performing of considered WT, dry season COWare 9.06, 
D. K. Kidmo et al.

Table 10. Average seasonal flow rate capacity $\left(\mathrm{m}^{4} / \mathrm{h}\right)$ using selected wind turbines at the twenty-one locations.

\begin{tabular}{|c|c|c|c|c|c|c|c|}
\hline Locations & Seasons & WT1 & WT2 & WT3 & WT4 & WT5 & WT6 \\
\hline \multirow{2}{*}{ Bogo } & Dry & 319.84 & 230.87 & 301.47 & 197.04 & 197.04 & 145.90 \\
\hline & Rainy & 52.21 & 37.58 & 38.50 & 16.82 & 16.82 & 12.43 \\
\hline \multirow{2}{*}{ Gazawa } & Dry & 326.75 & 240.25 & 304.20 & 199.29 & 199.29 & 149.99 \\
\hline & Rainy & 50.07 & 36.66 & 34.76 & 14.30 & 14.30 & 10.73 \\
\hline \multirow{2}{*}{ Maroua } & Dry & 296.91 & 213.08 & 279.64 & 181.32 & 181.32 & 133.61 \\
\hline & Rainy & 53.57 & 38.60 & 39.63 & 17.45 & 17.45 & 12.91 \\
\hline \multirow{2}{*}{ Ndoukoula } & Dry & 370.50 & 273.73 & 347.05 & 230.82 & 230.82 & 174.29 \\
\hline & Rainy & 49.18 & 36.11 & 33.68 & 13.64 & 13.64 & 10.27 \\
\hline \multirow{2}{*}{ Blangoua } & Dry & 585.99 & 430.35 & 568.37 & 396.24 & 396.24 & 294.75 \\
\hline & Rainy & 171.03 & 125.91 & 149.10 & 88.36 & 88.36 & 66.64 \\
\hline \multirow{2}{*}{ Darak } & Dry & 336.28 & 240.78 & 319.60 & 209.77 & 209.77 & 154.18 \\
\hline & Rainy & 59.98 & 43.09 & 45.92 & 21.24 & 21.24 & 15.67 \\
\hline \multirow{2}{*}{ Fotokol } & Dry & 465.50 & 336.65 & 448.29 & 303.94 & 303.94 & 224.43 \\
\hline & Rainy & 118.12 & 86.80 & 97.91 & 53.50 & 53.50 & 40.29 \\
\hline \multirow{2}{*}{ Goulfey } & Dry & 482.19 & 349.54 & 464.80 & 316.43 & 316.43 & 233.96 \\
\hline & Rainy & 111.26 & 81.35 & 92.18 & 49.93 & 49.93 & 37.43 \\
\hline \multirow{2}{*}{ Hile-Alifa } & Dry & 612.69 & 450.53 & 595.58 & 417.22 & 417.22 & 310.21 \\
\hline & Rainy & 197.83 & 146.03 & 174.90 & 106.29 & 106.29 & 80.36 \\
\hline \multirow{2}{*}{ Kousséri } & Dry & 483.08 & 350.91 & 465.29 & 317.06 & 317.06 & 234.85 \\
\hline & Rainy & 104.67 & 76.59 & 85.72 & 45.64 & 45.64 & 34.24 \\
\hline \multirow{2}{*}{ Logone-Birni } & Dry & 431.17 & 311.56 & 413.58 & 278.39 & 278.39 & 205.71 \\
\hline & Rainy & 76.64 & 55.66 & 60.16 & 29.57 & 29.57 & 22.04 \\
\hline \multirow{2}{*}{ Gobo } & Dry & 245.67 & 182.04 & 221.28 & 139.14 & 139.14 & 105.53 \\
\hline & Rainy & 42.11 & 30.93 & 27.55 & 10.39 & 10.39 & 7.82 \\
\hline \multirow{2}{*}{ Kalfou } & Dry & 326.75 & 240.25 & 304.20 & 199.29 & 199.29 & 149.99 \\
\hline & Rainy & 50.07 & 36.66 & 34.76 & 14.30 & 14.30 & 10.73 \\
\hline \multirow{2}{*}{ Maga } & Dry & 319.84 & 230.87 & 301.47 & 197.04 & 197.04 & 145.90 \\
\hline & Rainy & 52.21 & 37.58 & 38.50 & 16.82 & 16.82 & 12.43 \\
\hline \multirow{2}{*}{ Yagoua } & Dry & 293.85 & 215.63 & 271.71 & 175.71 & 175.71 & 132.07 \\
\hline & Rainy & 48.02 & 35.13 & 33.06 & 13.39 & 13.39 & 10.04 \\
\hline \multirow{2}{*}{ Mora } & Dry & 274.82 & 195.28 & 259.39 & 166.83 & 166.83 & 121.87 \\
\hline & Rainy & 65.19 & 46.95 & 50.49 & 23.92 & 23.92 & 17.69 \\
\hline \multirow{2}{*}{ Bourrha } & Dry & 391.27 & 293.97 & 363.47 & 243.49 & 243.49 & 186.50 \\
\hline & Rainy & 52.98 & 39.36 & 35.77 & 14.56 & 14.56 & 11.07 \\
\hline \multirow{2}{*}{ Hina } & Dry & 379.93 & 282.03 & 355.33 & 237.08 & 237.08 & 179.73 \\
\hline & Rainy & 51.48 & 38.07 & 34.96 & 14.21 & 14.21 & 10.76 \\
\hline \multirow{2}{*}{ Mokolo } & Dry & 290.04 & 207.92 & 272.97 & 176.56 & 176.56 & 129.99 \\
\hline & Rainy & 62.37 & 45.36 & 46.67 & 21.30 & 21.30 & 15.89 \\
\hline \multirow{2}{*}{ Dziguilao } & Dry & 326.75 & 240.25 & 304.20 & 199.29 & 199.29 & 149.99 \\
\hline & Rainy & 50.07 & 36.66 & 34.76 & 14.30 & 14.30 & 10.73 \\
\hline \multirow{2}{*}{ Kaélé } & Dry & 370.50 & 273.73 & 347.05 & 230.82 & 230.82 & 174.29 \\
\hline & Rainy & 49.18 & 36.11 & 33.68 & 13.64 & 13.64 & 10.27 \\
\hline
\end{tabular}


Table 11. Average seasonal flow rate capacity $\left(\mathrm{m}^{4} / \mathrm{h}\right)$ using selected wind turbines at the twenty-one locations.

\begin{tabular}{|c|c|c|c|c|c|c|c|}
\hline Locations & Seasons & WT1 & WT2 & WT3 & WT4 & WT5 & WT6 \\
\hline \multirow{2}{*}{ Bogo } & Dry & 133.80 & 69.71 & 118.86 & 50.78 & 50.78 & 27.84 \\
\hline & Rainy & 3.57 & 1.85 & 1.94 & 0.37 & 0.37 & 0.20 \\
\hline \multirow{2}{*}{ Gazawa } & Dry & 139.64 & 75.49 & 121.03 & 51.95 & 51.95 & 29.43 \\
\hline & Rainy & 3.28 & 1.76 & 1.58 & 0.27 & 0.27 & 0.15 \\
\hline \multirow{2}{*}{ Maroua } & Dry & 115.30 & 59.38 & 102.28 & 43.00 & 43.00 & 23.35 \\
\hline & Rainy & 3.75 & 1.95 & 2.05 & 0.40 & 0.40 & 0.22 \\
\hline \multirow{2}{*}{ Ndoukoula } & Dry & 179.54 & 98.00 & 157.53 & 69.68 & 69.68 & 39.73 \\
\hline & Rainy & 3.16 & 1.71 & 1.48 & 0.24 & 0.24 & 0.14 \\
\hline \multirow{2}{*}{ Blangoua } & Dry & 449.11 & 242.23 & 422.51 & 205.35 & 205.35 & 113.63 \\
\hline & Rainy & 38.26 & 20.73 & 29.08 & 10.21 & 10.21 & 5.81 \\
\hline \multirow{2}{*}{ Darak } & Dry & 147.90 & 75.83 & 133.59 & 57.55 & 57.55 & 31.09 \\
\hline & Rainy & 4.71 & 2.43 & 2.76 & 0.59 & 0.59 & 0.32 \\
\hline \multirow{2}{*}{ Fotokol } & Dry & 283.41 & 148.23 & 262.84 & 120.83 & 120.83 & 65.88 \\
\hline & Rainy & 18.25 & 9.86 & 12.54 & 3.74 & 3.74 & 2.12 \\
\hline \multirow{2}{*}{ Goulfey } & Dry & 304.10 & 159.80 & 282.56 & 130.96 & 130.96 & 71.59 \\
\hline & Rainy & 16.19 & 8.66 & 11.11 & 3.26 & 3.26 & 1.83 \\
\hline \multirow{2}{*}{ Hile-Alifa } & Dry & 490.96 & 265.48 & 463.94 & 227.67 & 227.67 & 125.86 \\
\hline & Rainy & 51.19 & 27.89 & 40.01 & 14.78 & 14.78 & 8.45 \\
\hline \multirow{2}{*}{ Kousséri } & Dry & 305.22 & 161.05 & 283.15 & 131.48 & 131.48 & 72.14 \\
\hline & Rainy & 14.33 & 7.67 & 9.61 & 2.72 & 2.72 & 1.53 \\
\hline \multirow{2}{*}{ Logone-Birni } & Dry & 243.15 & 126.96 & 223.72 & 101.36 & 101.36 & 55.34 \\
\hline & Rainy & 7.68 & 4.05 & 4.73 & 1.14 & 1.14 & 0.64 \\
\hline \multirow{2}{*}{ Gobo } & Dry & 78.93 & 43.34 & 64.04 & 25.32 & 25.32 & 14.57 \\
\hline & Rainy & 2.32 & 1.25 & 0.99 & 0.14 & 0.14 & 0.08 \\
\hline \multirow{2}{*}{ Kalfou } & Dry & 139.64 & 75.49 & 121.03 & 51.95 & 51.95 & 29.43 \\
\hline & Rainy & 3.28 & 1.76 & 1.58 & 0.27 & 0.27 & 0.15 \\
\hline \multirow{2}{*}{ Maga } & Dry & 133.80 & 69.71 & 118.86 & 50.78 & 50.78 & 27.84 \\
\hline & Rainy & 3.57 & 1.85 & 1.94 & 0.37 & 0.37 & 0.20 \\
\hline \multirow{2}{*}{ Yagoua } & Dry & 112.94 & 60.81 & 96.56 & 40.38 & 40.38 & 22.81 \\
\hline & Rainy & 3.02 & 1.61 & 1.43 & 0.23 & 0.23 & 0.13 \\
\hline \multirow{2}{*}{ Mora } & Dry & 98.78 & 49.87 & 88.00 & 36.40 & 36.40 & 19.43 \\
\hline & Rainy & 5.56 & 2.88 & 3.33 & 0.75 & 0.75 & 0.41 \\
\hline \multirow{2}{*}{ Bourrha } & Dry & 200.23 & 113.02 & 172.79 & 77.54 & 77.54 & 45.49 \\
\hline & Rainy & 3.67 & 2.03 & 1.67 & 0.28 & 0.28 & 0.16 \\
\hline \multirow{2}{*}{ Hina } & Dry & 188.79 & 104.03 & 165.13 & 73.52 & 73.52 & 42.25 \\
\hline & Rainy & 3.47 & 1.90 & 1.60 & 0.26 & 0.26 & 0.15 \\
\hline \multirow{2}{*}{ Mokolo } & Dry & 110.02 & 56.54 & 97.46 & 40.77 & 40.77 & 22.10 \\
\hline & Rainy & 5.09 & 2.69 & 2.85 & 0.59 & 0.59 & 0.33 \\
\hline \multirow{2}{*}{ Dziguilao } & Dry & 139.64 & 75.49 & 121.03 & 51.95 & 51.95 & 29.43 \\
\hline & Rainy & 3.28 & 1.76 & 1.58 & 0.27 & 0.27 & 0.15 \\
\hline \multirow{2}{*}{ Kaélé } & Dry & 179.54 & 98.00 & 157.53 & 69.68 & 69.68 & 39.73 \\
\hline & Rainy & 3.16 & 1.71 & 1.48 & 0.24 & 0.24 & 0.14 \\
\hline
\end{tabular}


D. K. Kidmo et al.

Table 12. Average seasonal costs of water $\left(\mathrm{XAF} / \mathrm{m}^{3}\right)$ at $50 \mathrm{~m}$ dynamic head using selected wind turbines at the twenty-one locations.

\begin{tabular}{|c|c|c|c|c|c|c|c|}
\hline Locations & Seasons & WT1 & WT2 & WT3 & WT4 & WT5 & WT6 \\
\hline \multirow{2}{*}{ Bogo } & Dry & 33.25 & 63.81 & 37.42 & 87.60 & 87.60 & 159.77 \\
\hline & Rainy & 1247.71 & 2408.57 & 2294.67 & $12,020.33$ & $12,020.33$ & $21,999.53$ \\
\hline \multirow{2}{*}{ Gazawa } & Dry & 31.86 & 58.92 & 36.76 & 85.64 & 85.64 & 151.18 \\
\hline & Rainy & 1356.83 & 2531.21 & 2814.24 & $16,629.19$ & $16,629.19$ & $29,520.65$ \\
\hline \multirow{2}{*}{ Maroua } & Dry & 38.58 & 74.91 & 43.49 & 103.45 & 103.45 & 190.51 \\
\hline & Rainy & 1185.19 & 2283.06 & 2165.19 & $11,172.28$ & $11,172.28$ & $20,408.97$ \\
\hline \multirow{2}{*}{ Ndoukoula } & Dry & 24.78 & 45.39 & 28.24 & 63.84 & 63.84 & 111.97 \\
\hline & Rainy & 1406.27 & 2607.89 & 2999.01 & $18,267.98$ & $18,267.98$ & $32,258.61$ \\
\hline \multirow{2}{*}{ Blangoua } & Dry & 9.91 & 18.36 & 10.53 & 21.66 & 21.66 & 39.15 \\
\hline & Rainy & 116.28 & 214.56 & 152.99 & 435.65 & 435.65 & 765.87 \\
\hline \multirow{2}{*}{ Darak } & Dry & 30.08 & 58.67 & 33.30 & 77.29 & 77.29 & 143.09 \\
\hline & Rainy & 945.32 & 1832.02 & 1613.20 & 7537.58 & 7537.58 & $13,843.82$ \\
\hline \multirow{2}{*}{ Fotokol } & Dry & 15.70 & 30.01 & 16.92 & 36.82 & 36.82 & 67.52 \\
\hline & Rainy & 243.77 & 451.39 & 354.80 & 1188.20 & 1188.20 & 2095.41 \\
\hline \multirow{2}{*}{ Goulfey } & Dry & 14.63 & 27.84 & 15.74 & 33.97 & 33.97 & 62.14 \\
\hline & Rainy & 274.77 & 513.90 & 400.31 & 1364.20 & 1364.20 & 2427.26 \\
\hline \multirow{2}{*}{ Hile-Alifa } & Dry & 9.06 & 16.76 & 9.59 & 19.54 & 19.54 & 35.35 \\
\hline & Rainy & 86.90 & 159.50 & 111.19 & 301.03 & 301.03 & 526.75 \\
\hline \multirow{2}{*}{ Kousséri } & Dry & 14.57 & 27.62 & 15.71 & 33.83 & 33.83 & 61.67 \\
\hline & Rainy & 310.47 & 579.86 & 462.93 & 1632.58 & 1632.58 & 2901.21 \\
\hline \multirow{2}{*}{ Logone-Birni } & Dry & 18.30 & 35.04 & 19.88 & 43.89 & 43.89 & 80.38 \\
\hline & Rainy & 579.12 & 1097.90 & 939.90 & 3888.83 & 3888.83 & 7003.30 \\
\hline \multirow{2}{*}{ Gobo } & Dry & 56.36 & 102.63 & 69.46 & 175.69 & 175.69 & 305.38 \\
\hline & Rainy & 1917.61 & 3555.46 & 4482.17 & $31,484.73$ & $31,484.73$ & $55,587.57$ \\
\hline \multirow{2}{*}{ Kalfou } & Dry & 31.86 & 58.92 & 36.76 & 85.64 & 85.64 & 151.18 \\
\hline & Rainy & 1356.83 & 2531.21 & 2814.24 & $16,629.19$ & $16,629.19$ & $29,520.65$ \\
\hline \multirow{2}{*}{ Maga } & Dry & 33.25 & 63.81 & 37.42 & 87.60 & 87.60 & 159.77 \\
\hline & Rainy & 1247.71 & 2408.57 & 2294.67 & $12,020.33$ & $12,020.33$ & $21,999.53$ \\
\hline \multirow{2}{*}{ Yagoua } & Dry & 39.39 & 73.15 & 46.07 & 110.17 & 110.17 & 194.99 \\
\hline & Rainy & 1474.71 & 2756.42 & 3112.30 & $18,978.68$ & $18,978.68$ & $33,749.27$ \\
\hline \multirow{2}{*}{ Mora } & Dry & 45.03 & 89.19 & 50.55 & 122.20 & 122.20 & 228.99 \\
\hline & Rainy & 800.28 & 1543.13 & 1334.01 & 5942.87 & 5942.87 & $10,865.80$ \\
\hline \multirow{2}{*}{ Bourrha } & Dry & 22.22 & 39.36 & 25.75 & 57.37 & 57.37 & 97.79 \\
\hline & Rainy & 1211.93 & 2195.16 & 2658.89 & $16,052.93$ & $16,052.93$ & $27,759.36$ \\
\hline \multirow{2}{*}{ Hina } & Dry & 23.56 & 42.76 & 26.94 & 60.51 & 60.51 & 105.29 \\
\hline & Rainy & 1283.32 & 2346.40 & 2782.86 & $16,854.70$ & $16,854.70$ & $29,390.10$ \\
\hline \multirow{2}{*}{ Mokolo } & Dry & 40.43 & 78.68 & 45.65 & 109.10 & 109.10 & 201.29 \\
\hline & Rainy & 874.35 & 1653.32 & 1561.86 & 7493.60 & 7493.60 & $13,464.00$ \\
\hline \multirow{2}{*}{ Dziguilao } & Dry & 31.86 & 58.92 & 36.76 & 85.64 & 85.64 & 151.18 \\
\hline & Rainy & 1356.83 & 2531.21 & 2814.24 & $16,629.19$ & $16,629.19$ & $29,520.65$ \\
\hline \multirow{2}{*}{ Kaélé } & Dry & 24.78 & 45.39 & 28.24 & 63.84 & 63.84 & 111.97 \\
\hline & Rainy & 1406.27 & 2607.89 & 2999.01 & $18,267.98$ & $18,267.98$ & $32,258.61$ \\
\hline
\end{tabular}




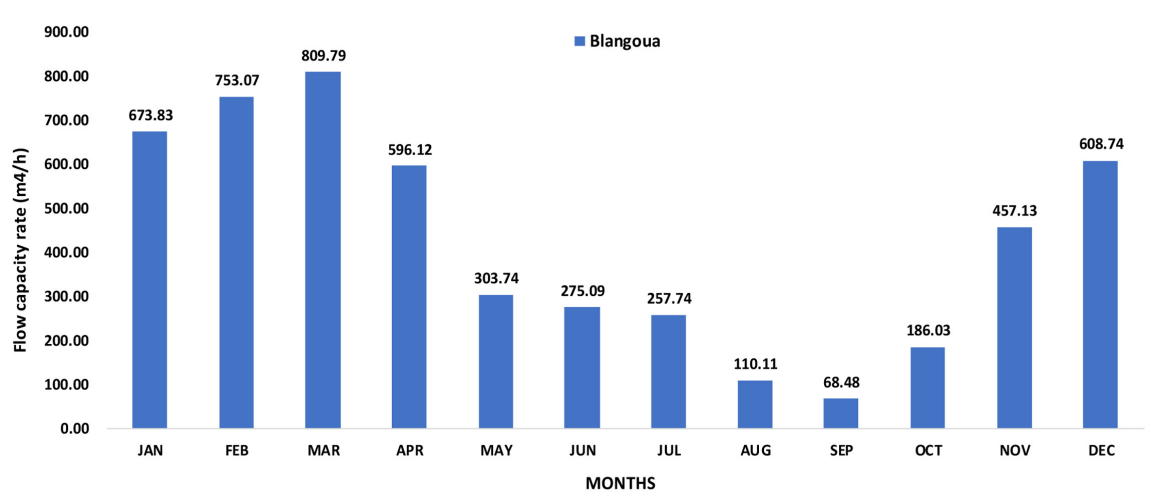

(a)

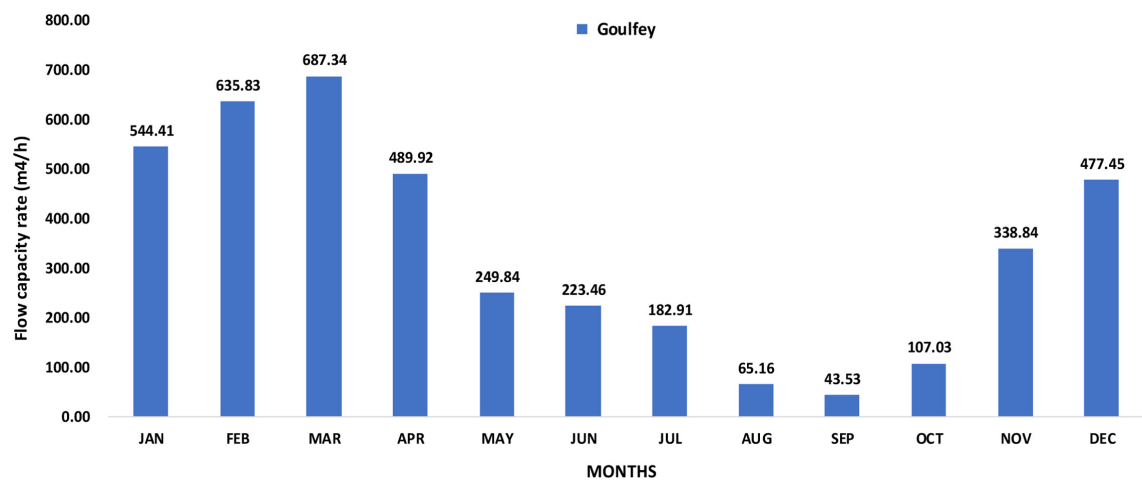

(b)

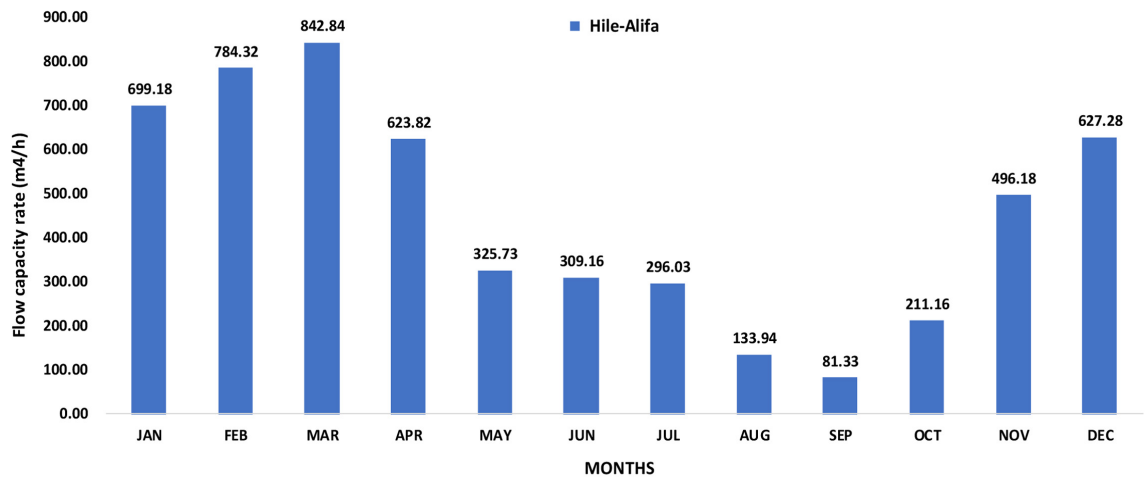

(c)

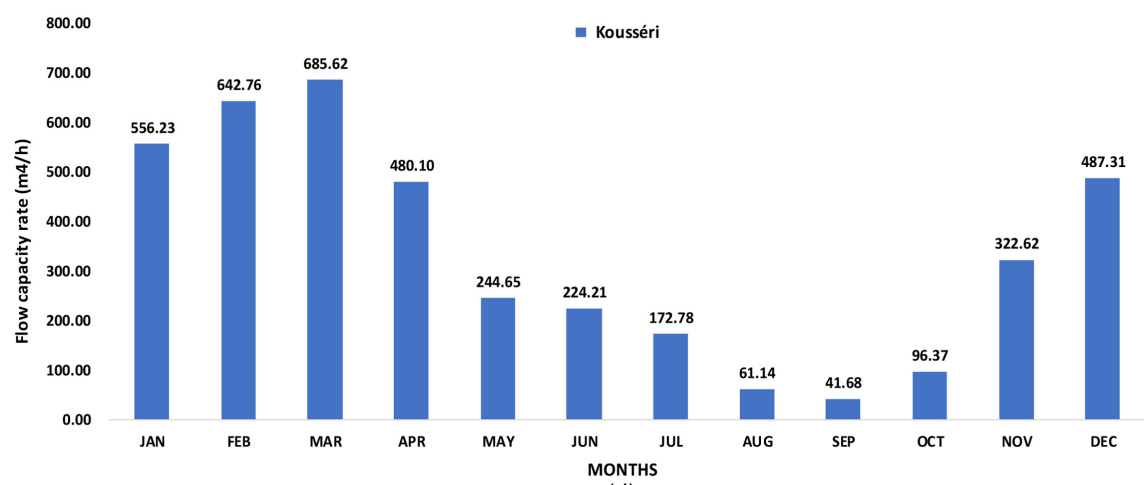

(d)

Figure 11. Average monthly flow rate capacity $\left(\mathrm{m}^{4} / \mathrm{h}\right)$ using WT1, at (a) Blangoua, (b) Goulfey, (c) Hilé-Alifa and (d) Kousseri. 


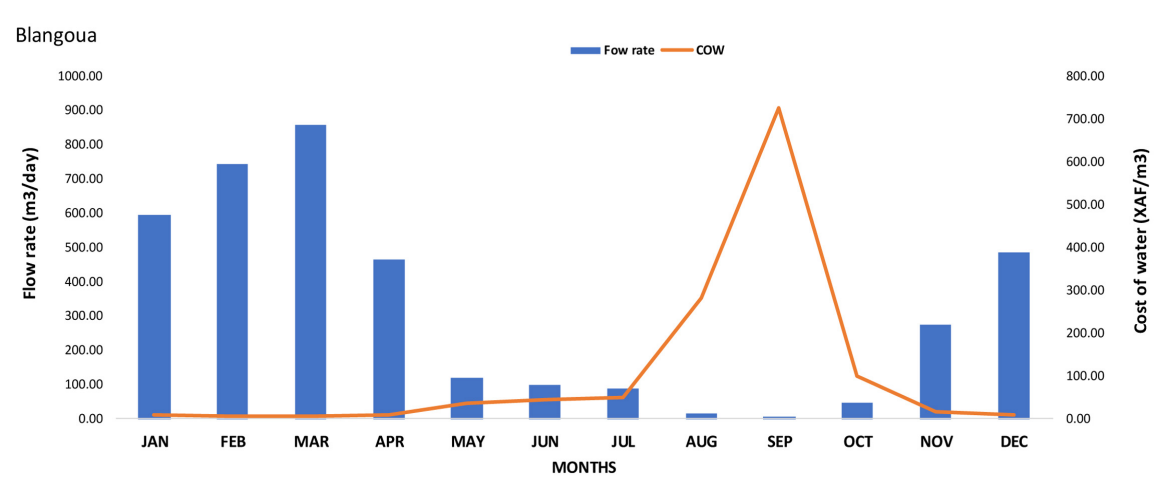

(a)

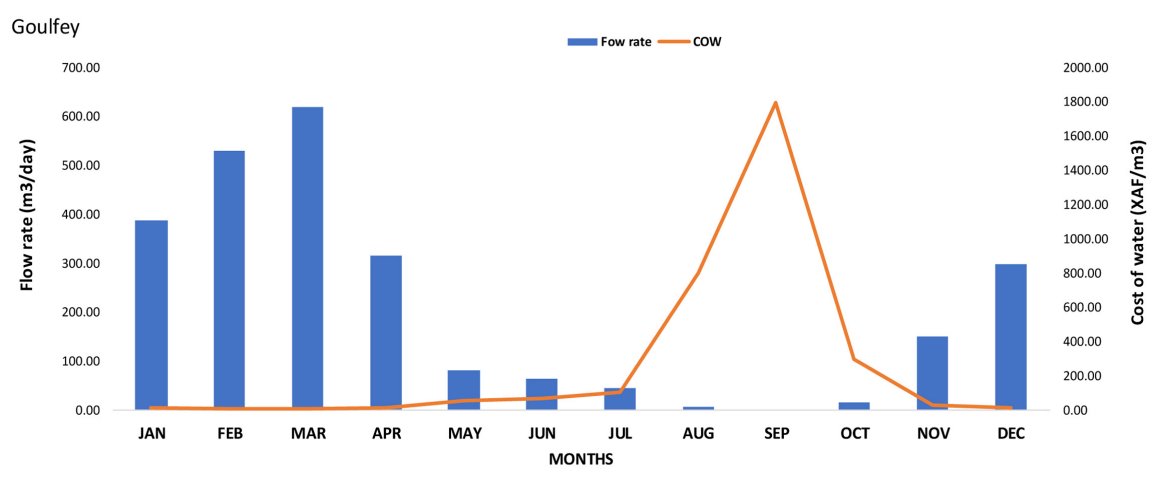

(b)

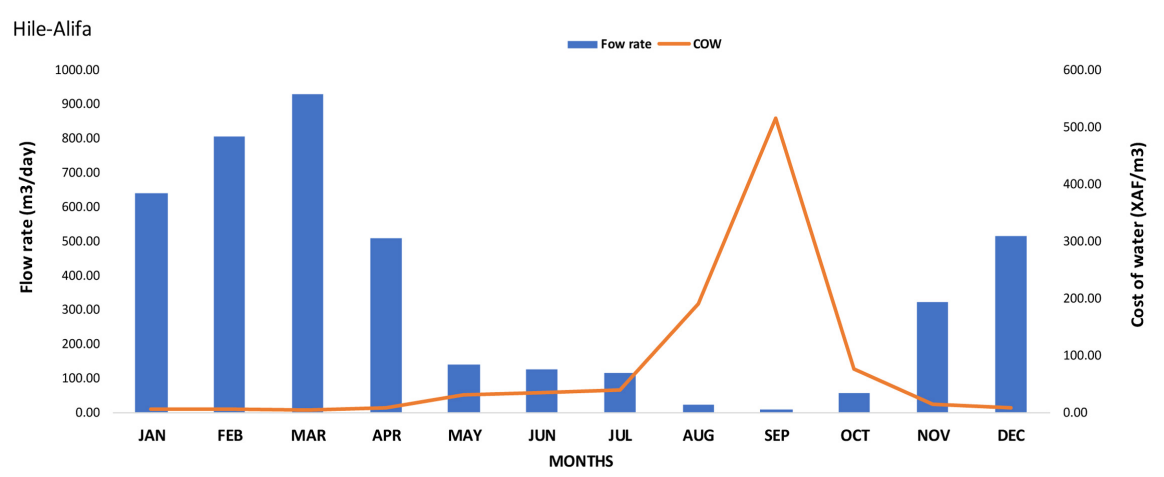

(c)

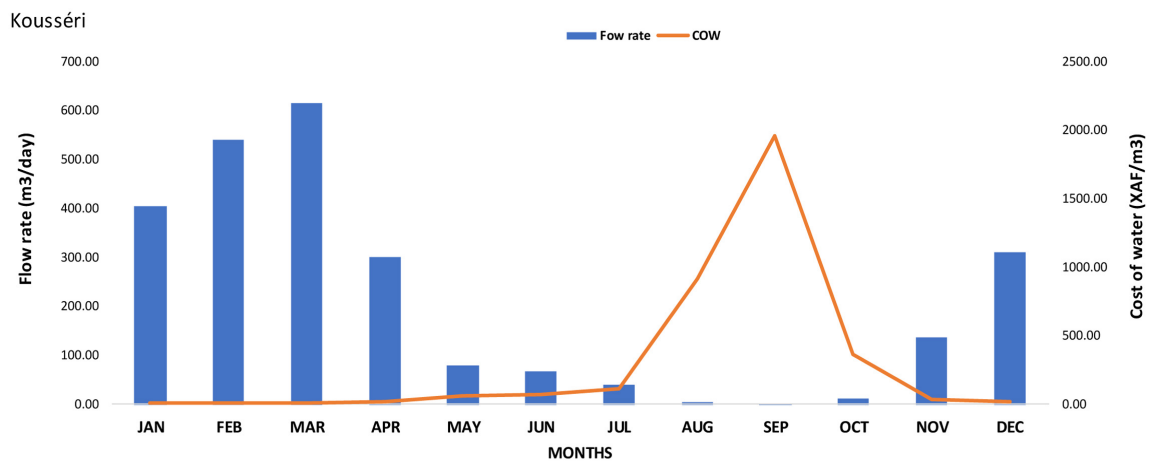

(d)

Figure 12. Average monthly COW and volumetric flow rate using WT1 for (a) Blangoua, (b) Goulfey, (c) Hilé-Alifa and (d) Kousseri. 
9.91, 14.57 and 14.63 XAF/m ${ }^{3}$ at Hile-Alifa, Blangoua, Kousseri and Goulfey, in that order. Rainy season corresponding values stand at $86.90,116.28,310.47$ and 274.77 XAF $/ \mathrm{m}^{3}$.

Figure 12 displays mean monthly $\mathrm{COW}$ and volumetric flow rate using $\mathrm{WT}_{1}$, at (a) Blangoua, (b) Goulfey, (c) Hilé-Alifa and (d) Kousseri. With respect to the PVC method, COW are inversely proportional to volumetric flow rate. It is observed that the higher the volumetric flow rate, the lower the COW. Lower COW are observed in dry season, whereas higher COW are experienced in rainy season. COW are highest in September and August, while March and February display the lowest COW.

\section{Conclusion}

In this work, seasonal wind characteristics, net energy production and performance of selected $10-\mathrm{kW}$ pitch-controlled WT in twenty-one selected locations in FNR have been evaluated using measured wind and satellite-derived wind data at $10 \mathrm{~m}$ height agl. Five reliable statistical indicators have been employed to assess the accuracy level of satellite-derived data. The 2-parameter Weibull PDF using the energy factor method provided the required tool to investigate seasonal wind characteristics, net energy production and performance of selected WT. The outcomes of this study show that mean wind speeds at $10 \mathrm{~m}$ height agl in FNR vary in the ranges of $2.99-4.32 \mathrm{~m} / \mathrm{s}, 2.12-3.23 \mathrm{~m} / \mathrm{s}, 3.43-4.87 \mathrm{~m} / \mathrm{s}$, respectively for yearly average, rainy and dry seasons. Satellite-based wind resource can be appropriate to assess the potential of wind energy in the early phase of wind farm projects, before higher-accuracy in-situ measurements are available. The wind resource in FNR is deemed suitable for wind pumping applications. Based on the hydraulic requirements for wind pumps, mechanical wind pumping system can be the most cost-effective option of wind pumping technologies in FNR. Wind electric pumping systems using WT, with cut-in WS (less than $2 \mathrm{~m} / \mathrm{s}$ ) and rated WS (less than $10 \mathrm{~m} / \mathrm{s}$ ) can be a cost-effective option for water pumping for four locations only, namely, Blangoua, Goulfey, Hilé-Alifa and Kousseri.

\section{Conflicts of Interest}

The authors declare no conflicts of interest regarding the publication of this paper.

\section{References}

[1] IRENA (2019) Future of Wind: Deployment, Investment, Technology, Grid Integration and Socio-Economic Aspects (A Global Energy Transformation Paper). Abu Dhabi.

[2] IRENA (2020) Renewable Capacity Highlights.

[3] IRENA (2020) Renewable Capacity Statistics 2020. Abu Dhabi.

[4] Ganda, F. and Ngwakwe, C.C. (2014) Problems of Sustainable Energy in Sub-Saharan Africa and Possible Solutions. Mediterranean Journal of Social Sciences, 5, 453-463. https://doi.org/10.5901/mjss.2014.v5n6p453 
[5] Mukasa, A.D., Mutambatsere, E., Arvanitis, Y. and Triki, T. (2013) Development of Wind Energy in Africa. Working Paper Series N ${ }^{\circ} 170$ African Development Bank, Tunis, Tunisia.

[6] Ackermann, T. (2000) Wind Energy Technology and Current Status: A Review. Renewable and Sustainable Energy Reviews, 4, 315-374. https://doi.org/10.1016/S1364-0321(00)00004-6

[7] IRENA (2020) Global Renewables Outlook: Energy Transformation 2050. Abu Dhabi.

[8] REN21 (2013) Renewables 2013 Global Status Report.

[9] Hasager, C.B., Mouche, A., Badger, M., Bingöl, F., Karagali, I., Driesenaar, T., et al. (2015) Remote Sensing of Environment Offshore Wind Climatology Based on Synergetic Use of Envisat ASAR, ASCAT and QuikSCAT. Remote Sensing of Environment, 156, 247-263. https://doi.org/10.1016/j.rse.2014.09.030

[10] Al Pet (2003) QuikSCAT Satellite Comparisons with Nearshore Buoy Wind Data off the U.S. West Coast. Journal of Atmospheric and Oceanic Technology, 20, 1869-1879. https://doi.org/10.1175/1520-0426(2003)020<1869:QSCWNB>2.0.CO;2

[11] Barthelmie, R.J. and Pryor, S.C. (2003) Can Satellite Sampling of Offshore Wind Speeds Realistically Represent Wind Speed Distributions? Journal of Applied Meteorology, 42, 83-94. https://doi.org/10.1175/1520-0450(2003)042<0083:CSSOOW >2.0.CO;2

[12] Id, L.Z., Shi, H., Wang, Z., Yu, H. and Yin, X. (2018) Comparison of Wind Speeds from Spaceborne Microwave Radiometers with in Situ Observations and ECMWF Data over the Global Ocean. Remote Sensing, 10, 425. https://doi.org/10.3390/rs10030425

[13] Remmers, T., Cawkwell, F., Desmond, C., Murphy, J. and Politi, E. (2019) The Potential of Advanced Scatterometer (ASCAT) $12.5 \mathrm{~km}$ Coastal Observations for Offshore Wind Farm Site Selection in Irish Waters. Energies, 12, 206. https://doi.org/10.3390/en12020206

[14] Schmidt, K.M., Swaart, S., Reason, C. and Nicholson, S.-A. (2017) Evaluation of Satellite and Reanalysis Wind Products with in Situ Wave Glider Wind Observations in the Southern Ocean. Journal of Atmospheric and Oceanic Technology, 34, 2551-2568. https://doi.org/10.1175/JTECH-D-17-0079.1

[15] National Institute of Statistics of Cameroon (2017) Statistical Yearbook 2017. Yaoundé.

[16] Wikipedia (2020) Geography of the Far North Region of Cameroon. Wikipedia. https://en.wikipedia.org/wiki/Far_North_Region_(Cameroon)\#Geography

[17] Britannica. Harmattan Wind 2020. http://global.britannica.com/science/harmattan

[18] NASA (2020) POWER Single Point Data Access. https://power.larc.nasa.gov/data-access-viewer

[19] Mohammadi, K., Mostafaeipour, A., Alavi, O., Goudarzi, N., Jalilvand, M., Mostafaeipour, A., et al. (2016) Assessing Different Parameters Estimation Methods of Weibull Distribution to Compute Wind Power Density. Energy Conversion and Management, 108, 322-335. https://doi.org/10.1016/j.enconman.2015.11.015

[20] Costa Rocha, P.A., de Sousa, R.C., de Andrade, C.F. and da Silva, M.E.V. (2012) Comparison of Seven Numerical Methods for Determining Weibull Parameters for Wind Energy Generation in the Northeast Region of Brazil. Applied Energy, 89, 395-400. https://doi.org/10.1016/j.apenergy.2011.08.003

[21] Bhattacharya, P. (2011) Weibull Distribution for Estimating the Parameters, Wind Energy Management. InTech, Rijeka. https://doi.org/10.5772/18151 
[22] Kidmo, D.K., Danwe, R., Doka, S.Y., Djongyang, N., Doka, Y.S. and Djongyang, N. (2015) Statistical Analysis of Wind Speed Distribution Based on Six Weibull Methods for Wind Power Evaluation in Garoua, Cameroon. Revue des Energies Renouvelables, 18, 105-125.

[23] Khahro, S.F., Tabbassum, K., Soomro, A.M., Dong, L. and Liao, X. (2014) Evaluation of Wind Power Production Prospective and Weibull Parameter Estimation Methods for Babaurband, Sindh Pakistan. Energy Conversion and Management, 78, 956-967. https://doi.org/10.1016/j.enconman.2013.06.062

[24] Azad, A., Rasul, M. and Yusaf, T. (2014) Statistical Diagnosis of the Best Weibull Methods for Wind Power Assessment for Agricultural Applications. Energies, 7, 3056-3085. https://doi.org/10.3390/en7053056

[25] Bilir, L., İmir, M., Devrim, Y. and Albostan, A. (2016) Seasonal and Yearly Wind Speed Distribution and Wind Power Density Analysis Based on Weibull Distribution Function Science Direct Seasonal and Yearly Wind Speed Distribution and Distribution Function. International Journal of Hydrogen Energy, 40, 15301-15310. https://doi.org/10.1016/j.ijhydene.2015.04.140

[26] De Meij, A., Vinuesa, J.-F., Maupas, V., Waddle, J., Price, I., Yaseen, B., et al. (2016) Wind Energy Resource Mapping of Palestine. Renewable and Sustainable Energy Reviews, 56, 551-562. https://doi.org/10.1016/j.rser.2015.11.090

[27] Stathopoulos, C., Kaperoni, A., Galanis, G. and Kallos, G. (2013) Wind Power Prediction Based on Numerical and Statistical Models. Journal of Wind Engineering \& Industrial Aerodynamics, 112, 25-38. https://doi.org/10.1016/j.jweia.2012.09.004

[28] Chang, T.P. (2010) Wind Speed and Power Density Analyses Based on Mixture Weibull and Maximum Entropy Distributions. International Journal of Applied Sciences and Engineering, 8, 39-46.

[29] Kidmo, D.K., Danwe, R., Djongyang, N. and Doka, S.Y. (2014) Comparison of Five Numerical Methods for Estimating Weibull Parameters for Wind Energy Applications in the District of Kousseri, Cameroon. Asian Journal of Natural \& Applied Sciences, 3, 72-87.

[30] Neme, C. (2013) Statistical Analysis of Wind Speed Profile: A Case Study from Iasi Region. Romania, 3, 261-268. https://doi.org/10.5963/IJEE0306007

[31] Ayodele, T.R.R., Jimoh, A.A., Munda, J.L.L. and Agee, J.T.T. (2012) Wind Distribution and Capacity Factor Estimation for Wind Turbines in the Coastal Region of South Africa. Energy Conversion and Management, 64, 614-625.

https://doi.org/10.1016/j.enconman.2012.06.007

[32] Gualtieri, G. and Secci, S. (2012) Methods to Extrapolate Wind Resource to the Turbine Hub Height Based on Power Law: A 1-h Wind Speed vs. Weibull Distribution Extrapolation Comparison. Renewable Energy, 43, 183-200. https://doi.org/10.1016/j.renene.2011.12.022

[33] Mostafaeipour, A., Jadidi, M., Mohammadi, K. and Sedaghat, A. (2014) An Analysis of Wind Energy Potential and Economic Evaluation in Zahedan, Iran. Renewable and Sustainable Energy Reviews, 30, 641-650. https://doi.org/10.1016/j.rser.2013.11.016

[34] Ohunakin, O.S.S., Adaramola, M.S.S. and Oyewola, O.M.M. (2011) Wind Energy Evaluation for Electricity Generation Using WECS in Seven Selected Locations in Nigeria. Applied Energy, 88, 3197-3206. https://doi.org/10.1016/j.apenergy.2011.03.022

[35] Bailey, B., McDonald, S., Bernadett, D., Markus, M. and Elsholz, K. (1997) Wind Resource Assessment Handbook: Fundamentals for Conducting a Successful Monitoring Program. Music Educators Journal, 41, 65.

https://doi.org/10.2172/486127 
[36] Mathewand, S., Philip, G.S. and Lim, C.M. (2011) Analysis of Wind Regimes and Performance of Wind Turbines. In: Advances in Wind Energy Conversion Technology, Springer, Berlin, 71-83. https://doi.org/10.1007/978-3-540-88258-9_2

[37] Adaramola, M.S., Oyewola, O.M., Ohunakin, O.S. and Akinnawonu, O.O. (2014) Performance Evaluation of Wind Turbines for Energy Generation in Niger Delta, Nigeria. Sustainable Energy Technologies and Assessments, 6, 75-85. https://doi.org/10.1016/j.seta.2014.01.001

[38] Akpinar, E.K. and Akpinar, S. (2005) An Assessment on Seasonal Analysis of Wind Energy Characteristics and Wind Turbine Characteristics. Energy Conversion and Management, 46, 1848-1867. https://doi.org/10.1016/j.enconman.2004.08.012

[39] Paul, S.S., Oyedepo, S.O. and Adaramola, M.S. (2012) Economic Assessment of Water Pumping Systems Using Wind Energy Conversions in the Southern Part of Nigeria. Energy Exploration \& Exploitation, 30, 1-18.

https://doi.org/10.1260/0144-5987.30.1.1

[40] Rehman, S., Halawani, T.O. and Mohandes, M. (2003) Wind Power Cost Assessment at Twenty Locations in the Kingdom of Saudi Arabia. Renewable Energy, 28, 573-583. https://doi.org/10.1016/S0960-1481(02)00063-0

[41] Diaf, S., Notton, G. and Diaf, D. (2013) Technical and Economic Assessment of Wind Farm Power Generation at Adrar in Southern Algeria. Energy Procedia, 42, 53-62. https://doi.org/10.1016/j.egypro.2013.11.005

[42] Mathew, S. (2007) Wind Energy: Fundamentals, Resource Analysis and Economics.

[43] Smulders, P.T. (1996) Wind Water Pumping: The Forgotten Option. Energy for Sustainable Development, 2, 8-13. https://doi.org/10.1016/S0973-0826(08)60156-8 


\section{Nomenclature}

\begin{tabular}{|c|c|c|c|}
\hline$v_{m}$ & Mean wind speed $[\mathrm{m} / \mathrm{s}]$ & $v_{i}$ & Wind speed $[\mathrm{m} / \mathrm{s}]$ \\
\hline$k_{10}$ & Shape parameter at $10 \mathrm{~m}$ height agl $[-]$ & $N$ & Number of wind speed data \\
\hline$k_{z}$ & Shape parameter at $\mathbf{z}$ meters height agl [-] & $v$ & Wind speed $[\mathrm{m} / \mathrm{s}]$ \\
\hline$\sigma$ & Standard deviation of the mean wind speed $[\mathrm{m} / \mathrm{s}]$ & $n$ & Power law exponent [-] \\
\hline$n$ & Useful lifetime of WT in years (20 years) [year] & $v_{c}$ & Cut-in wind speed $[\mathrm{m} / \mathrm{s}]$ \\
\hline$F_{w}$ & Water pumping capacity rate $\left[\mathrm{m}^{4} / \mathrm{h}\right]$ & $v_{R}$ & Rated wind speed $[\mathrm{m} / \mathrm{s}]$ \\
\hline$v_{m G}$ & Measured wind speed $[\mathrm{m} / \mathrm{s}]$ & $v_{F}$ & Cut-off wind speed $[\mathrm{m} / \mathrm{s}]$ \\
\hline$\sigma_{G}$ & Standard deviation of the mean measured WS $[\mathrm{m} / \mathrm{s}]$ & $P_{e R}$ & Rated electrical power $[\mathrm{kW}]$ \\
\hline$v_{m s}$ & Satellite-derived wind speed $[\mathrm{m} / \mathrm{s}]$ & $P_{e, a v e}$ & Average power output $[\mathrm{kW}]$ \\
\hline$\sigma_{s}$ & Standard deviation of the mean satellite-derived WS $[\mathrm{m} / \mathrm{s}]$ & $Q_{w}$ & Volumetric flow rate (mday) \\
\hline$f(v)$ & Probability of observing wind speed $v$ & $\rho_{w}$ & Water density $\left[\mathrm{kg} / \mathrm{m}^{3}\right]$ \\
\hline$g$ & Acceleration due to gravity $\left[\mathrm{m} / \mathrm{s}^{2}\right]$ & $\overline{S a t_{i}}$ & Mean value of $S a t_{i}$ \\
\hline$C$ & Weibull scale parameter $[\mathrm{m} / \mathrm{s}]$ & $H$ & Pump head [m] \\
\hline$k$ & Weibull shape parameter [-] & $\eta$ & System efficiency [-] \\
\hline$E_{p f}$ & Energy pattern factor $[-]$ & PVC & Present value of costs $[\mathrm{XAF}]$ \\
\hline MBE & Mean Bias Error [-] & $\eta_{\text {PUMP }}$ & Efficiency of the pump [-] \\
\hline RRMSE & Relative root mean square error [\%] & $P_{\text {out }}$ & Net hydraulic power output $[\mathrm{kW}]$ \\
\hline $\mathrm{R}^{2}$ & Coefficient of determination [-] & $I$ & Investment cost [XAF] \\
\hline$G r_{i}$ & $i^{\text {th }} \mathrm{CFD}$ of ground (measured) wind speeds & $i_{o}$ & Nominal interest rate [\%] \\
\hline Sat $_{i}$ & $I^{t h} \mathrm{CFD}$ of satellite-derived wind speeds & $S$ & Scrap value $[\%]$ \\
\hline$C_{\text {om }}$ & Operation and maintenance costs [\%] & $I$ & Inflation rate [\%] \\
\hline$N$ & Number of non-zero wind speed data points & $r$ & Discount rate $[\%]$ \\
\hline$C_{10}$ & Scale parameter at $10 \mathrm{~m}$ height agl $[\mathrm{m} / \mathrm{s}]$ & $\mathrm{COE}$ & Cost of energy [XAF/kWh] \\
\hline$C_{z}$ & Scale parameter at $\mathbf{z}$ meters height agl $[\mathrm{m} / \mathrm{s}]$ & COW & Cost of water $\left[\mathrm{XAF} / \mathrm{m}^{3}\right]$ \\
\hline$E_{W T}$ & Total energy output over the WT lifetime [kWh] & IOA & Index of Agreement \\
\hline$V_{w}$ & Annual volume of water $\left[\mathrm{m}^{3} /\right.$ year $]$ & RMSE & Root mean square error [-] \\
\hline
\end{tabular}

